\title{
Acetazolamide potentiates the anti-tumor potential of HDACi, MS-275, in neuroblastoma
}

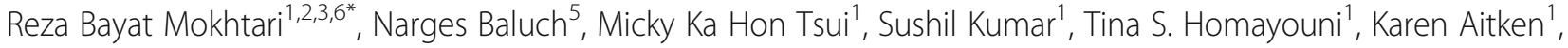
Bikul Das ${ }^{6}$, Sylvain Baruchel ${ }^{4}$ and Herman Yeger ${ }^{1,2,3^{*}}$

\begin{abstract}
Background: Neuroblastoma (NB), a tumor of the primitive neural crest, despite aggressive treatment portends a poor long-term survival for patients with advanced high stage NB. New treatment strategies are required.

Methods: We investigated coordinated targeting of essential homeostatic regulatory factors involved in cancer progression, histone deacetylases (HDACs) and carbonic anhydrases (CAs).

Results: We evaluated the antitumor potential of the HDAC inhibitor (HDACi), pyridylmethyl-N-\{4-[(2-aminophenyl)carbamoyl]-benzyl\}-carbamate (MS-275) in combination with a pan CA inhibitor, acetazolamide (AZ) on NB SH-SY5Y, SK-N-SH and SK-N-BE(2) cells. The key observation was that the combination AZ + MS-275 significantly inhibited growth, induced cell cycle arrest and apoptosis, and reduced migration capacity of NB cell line SH-SY5Y. In addition, this combination significantly inhibited tumor growth in vivo, in a pre-clinical xenograft model. Evidence was obtained for a marked reduction in tumorigenicity and in the expression of mitotic, proliferative, HIF-1a and CAIX. NB xenografts of SH-SY5Y showed a significant increase in apoptosis.

Conclusion: MS-275 alone at nanomolar concentrations significantly reduced the putative cancer stem cell (CSC) fraction of NB cell lines, SH-SY5Y and SK-N-BE(2), in reference to NT2/D1, a teratocarcinoma cell line, exhibiting a strong stem cell like phenotype in vitro. Whereas stemness genes (OCT4, SOX2 and Nanog) were found to be significantly downregulated after MS-275 treatment, this was further enhanced by AZ co-treatment. The significant reduction in initial tumorigenicity and subsequent abrogation upon serial xenografting suggests potential elimination of the NB CSC fraction. The significant potentiation of MS-275 by AZ is a promising therapeutic approach and one amenable for administration to patients given their current clinical utility.
\end{abstract}

Keywords: Neuroblastoma, Histone deacetylases, Carbonic anhydrases, HDAC inhibitor, Acetazolamide, MS-275

\section{Background}

Neuroblastoma (NB) is a tumor derived from the primitive neural crest that forms the peripheral sympathetic nervous system. Despite aggressive treatment long-term survival for high-risk NB is less than $40 \%$, due mainly to metastasis and relapse [1]. Intensive multimodal therapy has failed to improve long-term survival significantly [1]. Although NB constitutes only $7 \%$ of pediatric malignancies, it accounts for more than $10 \%$ of mortality from

\footnotetext{
* Correspondence: reza.mokhtari@sickkids.ca; hermie@sickkids.ca ${ }^{1}$ Developmental and Stem Cell Biology, The Hospital for Sick Children, Toronto, ON, Canada

Full list of author information is available at the end of the article
}

childhood cancer [1]. Therefore, newer treatment strategies are needed to address the therapeutic challenges of this highly aggressive pediatric cancer. As expression of both carbonic anhydrases (CA) and histone deacetylases (HDACs) are reported to be elevated in $\mathrm{NB}$, they represent potential novel therapeutic targets for NB [1-3]. The benzamide class I specific HDAC inhibitor (HDACi), pyridylmethyl-N\{4-[(2-aminophenyl)carbamoyl]-benzyl\}-carbamate (MS-275) alone or in combination with other compounds (ex. azacytidine, an inhibitor of DNA methylation), has been in clinical trials for leukemia and other solid tumors $[4,5]$. HDACi has been proven to be effective in NB preclinical 
studies [6]. MS-275 is noted for its potent anti-cancer abilities, long serum half life, and selective HDACi properties [7]. In particular, Jaboin et al. reported that MS-275 induced apoptosis of NB KNCR in vitro after $48 \mathrm{~h}$, and significantly reduced growth of adrenal orthotopic xenografts [8]. MS-275 decreased cell viability and induced differentiation of NB cell lines (BE(2)-C and Kelly) $[9,10]$. Other studies have shown synergistic effects of HDACi with some of the conventional chemotherapeutic agents [11].

Maintaining $\mathrm{pH}$ homeostasis, as governed by carbonic anhydrases (CAs) [12] is essential for tumor cell survival and progression. One of the $15 \mathrm{CA}$ isoforms, CAIX, is associated with malignant progression and metastasis [12]. CAIX in particular correlates with metastasis and tumor progression, in many cancers including NB $[12,13]$. Further, upregulation of HIF1- $\alpha$ in the hypoxic tumor microenvironment upregulates CAIX, its downstream target [12, 14]. This occurs in NB cell lines exposed to chronic hypoxia [13]. In NB patients higher expression of membrane CAIX in NB biopsies is inversely associated with overall survival and event free survival [13]. In addition, higher levels of membrane CAIX are correlated with the less well-differentiated phenotype, MYCN amplification and unfavorable pathology [14]. The critical role of CAs in tumor survival has encouraged research into the efficacy of CA inhibitors against several types of cancer [15].

The pan-CA inhibitor, acetazolamide (AZ), is routinely administered for the treatment of high altitude sickness and glaucoma [16]. We previously reported that AZ reduces cell viability colony formation, and inhibited tumor growth in lung carcinoid and bladder cancer cell lines in a concentration-dependent manner [17]. In these studies AZ potentiated the anti-tumor effect of sulforaphane, an isothiocyanate with HDACi activity. In human renal carcinoma and cervical cancer cells, AZ and AZ-based derivatives, as single agent or in combination therapy with synthesized aromatic sulfonamides with high affinity for CAIX demonstrated antitumor activity including inhibition of cell proliferation, induction of apoptosis and suppression of tumor cell invasiveness $[18,19]$.

More recent evidence suggests that combining a carbonic anhydrase inhibitor with a HDACi might indeed be more effective than either agent alone since they target different steps in the response of tumor cells to hypoxia prevalent in almost all cancers [17, 20]. In fact, the hypoxic microenvironment positively enhances expansion of cancer stem cells (CSCs) where upregulation of HIF1- $\alpha$ drives expression of CAIX associated with CSC expansion [21, 22]. Further, MS-275 can increase senescence in mesenchymal stem cells, and decreases expression of stemness genes (e.g. Sall-4 and BMI-1) [23]. Therefore, we postulated that combining AZ with
MS-275, a potent selective HDACi, would be more effective than either single agent alone against NB. MS275 at low $\mu \mathrm{M}$ concentrations has previously been shown to negatively affect $\mathrm{NB}$ cell viability in vitro [8]. We confirmed this observation and provide evidence of the ability of AZ to significantly potentiate the MS-275 HDACi effect on NB in vitro and in vivo.

\section{Methods \\ Materials}

Acetazolamide (AZ), cisplatin (CDDP), dimethyl sulfoxide (DMSO) and MS-275 were obtained from Sigma-Aldrich (Oakville, ON, Canada). Culture media, AMEM, DMEM/ F12 and DMEM, and supplements, fetal bovine serum (FBS) and penicillin-streptomycin, were purchased from Gibco (Burlington, ON, Canada). Bovine serum albumin (BSA) was obtained from Invitrogen (Grand Island, NY, USA). Matrigel was purchased from BD Biosciences company (La Jolla, CA, USA). Methylcellulose was obtained from StemCell Technologies (Vancouver, BC, Canada) and phosphate buffered saline (PBS) from Multicell (St. Bruno, QC, Canada).

\section{Cell lines}

Cells were purchased from the American Type Culture Collection (ATCC) as follow: N-type, MYCN nonamplified SH-SY5Y (CRL-2266) and SK-N-SH (HTB-11) and MYCN amplified, SK-N-BE(2) (CRL-2271), and teratocarcinoma NT2/D1 (CRL-1973). Cells were cultured in AMEM (SH-SY5Y and SK-N-BE(2)) and DMEM/F12 (NT2/D1) supplemented with 10\% fetal bovine serum and $1 \%$ penicillin/streptomycin (Multicell, St. Bruno, Quebec) at $37{ }^{\circ} \mathrm{C}$ in a humidified atmosphere of $5 \% \mathrm{CO}_{2}$. Reference normal neuronal stem cell strains (NSC6539 and NSC6562) were kindly provided by Dr. Peter Dirks (SickKids) and maintained in Neurocult and Neuronal stem cell Expansion media-Human from Stemcell Technologies (Stemcell Technologies,Vancouver, BC, Canada) supplemented with $2 \mathrm{mM}$ L-Glutamine, $75 \mu \mathrm{g} / \mathrm{ml} \mathrm{BSA}$, $10 \mathrm{ng} / \mathrm{ml}$ (B27, EGF and FGF), $2 \mu \mathrm{M} / \mathrm{ml}$ heparin and $1 \%$ penicillin/streptomycin (Multicell, St. Bruno, Quebec, Canada). The cells were grown on poly-L-ornithine and laminin (Sigma-Aldrich, Oakville, ON, Canada) coated plates at $37{ }^{\circ} \mathrm{C}$ and $5 \% \mathrm{CO}_{2}$. The cells were fed every $3-4$ days.

\section{Trypan blue exclusion assay}

Standard procedures were performed as described [17]. Briefly, cell viability was assessed by trypan blue exclusion assay by observing the number of trypan blue positive cells versus total cells counter per microscopic field. 


\section{AlamarBlue cytotoxicity assay}

Standard protocol was performed as described [17]. Percent survival vs. control (DMSO- $0.2 \times 10^{-4} \mu \mathrm{M}$ ) of cells when treated with AZ, MS-275 and AZ + MS-275 were observed using AlamarBlue agent (AbD Serotec, MorphoSys, Raleigh, NC, USA) agent ( $10 \%$ of total volume) was added to each well for $4 \mathrm{~h}$ before fluorometric detection. Fluorescence was measured using the SPECTRAmax Gemini Spectrophotometer (excitation $540 \mathrm{~nm}$; emission $590 \mathrm{~nm}$ ).

\section{In-cell western assay}

$10^{5}$ cells were seeded into 96 well plates and treated for $48 \mathrm{~h}$ with $1.5 \mu \mathrm{M}$ MS-275. Following treatment, cells were washed twice with PBS and fixed with $4 \%$ paraformaldehyde for $20 \mathrm{~min}$. Cells were then permeabilized with $0.1 \%$ Triton-X 100 for 5 min and washed twice with PBS. Cells were blocked in 1x Odyssey blocking buffer (LI-COR, Guelph, ON, Canada) for $2 \mathrm{~h}$ at room temperature. Primary antibodies against p16 (1/50; Santa Cruz, Santa Cruz, CA, USA), p21 (1/20; Santa Cruz, Santa Cruz, CA, USA), p27 (1/20; Santa Cruz, Santa Cruz, CA, USA), BCL-2 (1/100; Cell Signaling Technology, Toronto, ON, Canada), cyclin D1 (1/10; Neomarkers/ Lab Vision,ThermoScientific, Fremont, CA, USA), and CDK4 (1/100; Neomarkers/Lab Vision,ThermoScientific, Fremont, CA, USA) were diluted in Odyssey blocking buffer at indicated ratios and added to cells overnight at $4{ }^{\circ} \mathrm{C}$. Pan-actin antibody (1/100; CEDARLANE, Burlington, Ontario, Canada) was also added in conjunction with the other antibodies to serve as a control of cell content. Cells were then washed with a $0.1 \%$ Tween 20 (Fisher Scientific Co, Markham, ON, Canada) solution for $5 \mathrm{~min}$ and repeated five times. Fluorescently labeled Li-COR secondary antibody (Goat-anti-Rabbit IRDye 680; LI-COR, Guelph, ON, Canada), (Goat-anti-Mouse IRDye 800; LI-COR, Guelph, ON, Canada) were then added at a dilution of $1 / 500$ and cells treated for $1 \mathrm{~h}$ at RT. In wells where actin was not used as a cell content control, DRAQ5/ Sapphire700 were added at $1 \mathrm{mM}$ and $1 / 1000$ dilution respectively. Cells were then again washed with $0.1 \%$ Tween 20 solution five times for $5 \mathrm{~min}$. Cells were imaged on the Odyssey Infrared Imaging System at excitation of $700 \mathrm{~nm}$ and $800 \mathrm{~nm}$. Total fluorescence was quantified and adjusted to cell content control of either actin or DRAQ5/Sapphire700.

\section{Propidium lodide cell cycle assay}

Briefly, $2 \times 10^{6}$ cells treated with AZ and/or MS-275 were lifted by citrate saline and fixed in $80 \%$ ice-cold ethanol for $48 \mathrm{~h}$. Cells were then pelleted and re-suspended in $2 \mathrm{mg} / \mathrm{mL}$ RNase A (Sigma-Aldrich, Oakville, ON, Canada) for $5 \mathrm{~min}$. A $0.1 \mathrm{mg} / \mathrm{mL}$ propidium iodide solution (Sigma-Aldrich, Oakville, ON, Canada) was added, incubated for $30 \mathrm{~min}$ at RT, and cells filtered through a cell-strainer into a $5 \mathrm{~mL}$ polystyrene tube. Labeled cells were analyzed on a BD FACSCAN flow cytometer. Data was fitted by the Watson-Pragmatic model on FlowJo Software (Tree Star, Ashland, OR, USA).

\section{Methylcellulose clonogenic assay}

Standard protocol was performed as follows [17], cultures were trypsinized and single cells were suspended in methycellulose medium (Methocult; StemCell Technologies, Vancouver, BC, Canada). In this process, $1.2 \times 10^{4}$ SH-SY5Y, $7.5 \times 10^{3}$ SK-N-BE(2) and $2 \times 10^{3}$ NT2/D1 cells/mL were placed into a $40 \%$ methycellulose solution supplemented with $10 \%$ FBS, $1 \%$ antibiotics and $49 \%$ culture medium. MS-275 concentrations ranging from $10 \mathrm{nM}$ to $3 \mu \mathrm{M}$ were added to the methycellulose. Cells in methylcellulose were gently vortexed and distributed into non-adherent $35 \mathrm{~mm}$ tissue culture dishes with a blunt end 16 gauge needle. Samples were placed in a $37{ }^{\circ} \mathrm{C}$ incubator in $5 \% \mathrm{CO}_{2}$. After 2 weeks colonies were photographed and counted on a phase contrast microscope using a grading dish. Clonogenicity was determined as the average of number of colonies per dish for each group of cells.

\section{Side Population (SP) assay}

Briefly, $10^{6}$ cells $/ \mathrm{ml}$ were lifted with citrate saline $(0.05 \mathrm{M})$ and incubated for $1.5 \mathrm{~h}$ with $5 \mu \mathrm{g} / \mathrm{mL}$ Hoechst 33342 (bisbenzimide trihydrochloride); (Sigma-Aldrich, Oakville, ON, Canada) in a $37{ }^{\circ} \mathrm{C}$ water bath. Negative controls were prepared by prior addition of $50 \mu \mathrm{M}$ Verapamil HCl (Sigma-Aldrich, Oakville, ON, Canada), calcium channel blocker. Cells were washed, counterstained with $1 \mu \mathrm{g} / \mathrm{mL}$ propidium iodide (Sigma-Aldrich, Oakville, ON, Canada) and analyzed on a BD LSRII flow cytometric analyzer.

\section{Flow cytometry for cell surface $A B C G 2$}

For flow cytometry, $10^{5}$ cells $/ \mathrm{ml}$ were lifted with trypsin and were blocked in cold $5 \%$ BSA/PBS solution at $4{ }^{\circ} \mathrm{C}$ for $15 \mathrm{~min}$. Next, cells were treated with anti-ABCG2 conjugated to phycoerythrin (R\&D Systems, Mineapolis, MN, USA) for $45 \mathrm{~min}$. After being washed three times with cold PBS, cells were resuspended in PBS solution containing 7-AAD (BD Pharmingen, San Jose, CA, USA) and then analyzed on a BD LSRII flow cytometric analyzer. Cells negative for 7-AAD were gated to exclude non-viable cells. Gating was determined from the negative trypsin controls.

\section{Flow cytometry for OCT4, SOX2, Nanog}

Adherent cells were lifted by trypsin, washed and fixed with 4\% paraformaldehyde (Canemco, St. Laurent, Quebec, Canada) in PBS. $3 \times 10^{6}$ cells were permeabilized with $0.1 \%$ 
Triton-X in PBS, washed twice with PBS and blocked with $5 \% \mathrm{BSA} / \mathrm{PBS}$ solution for $1 \mathrm{~h}$ at RT. Cells were incubated overnight at $4{ }^{\circ} \mathrm{C}$ in primary antibody against OCT4 (1/200; Cell Signaling, Danvers, MA, USA), SOX2 (1/ 200; R\&D Systems, Mineapolis, MN, USA) or Nanog (1/200; Cell Signaling Technology, Toronto, ON, Canada) in $5 \% \mathrm{BSA} / \mathrm{PBS}$. Cells were subsequently washed three times with $\mathrm{PBS}$ and incubated with a chicken-anti-rabbit Alexa Fluor-488 (1/3500; Invitrogen, Carlsbad, CA, USA) or goat-anti-mouse R-Phycoerythrin (1/500; Caltag, Burlingame, CA, USA) secondary antibody in 5\% BSA/ $\mathrm{PBS}$, for $1 \mathrm{~h}$ in room temperature. Cells were washed and analyzed on a BD FACSCAN flow cytometer.

\section{Immunofluorescence labeling}

Cells were grown on glass coverslips until $75 \%$ confluent and then treated with MS-275. Immunofluorescence was performed [24] with primary antibodies to OCT4 (1/300; Cell Signaling Technology, Toronto, ON, Canada), SOX2 (1/250; R\&D Systems, Minneapolis, MN, USA) and Nanog (1/200; Cell Signaling Technology, Toronto, ON, Canada) followed by incubation in AlexaFluor secondary antibodies (Invitrogen, Grand Island, NY, USA), and mounting in PBS/glycerol.

\section{Western blot analysis}

Cells were lysed with RIPA extraction buffer (MBiotech, Seoul, Korea) supplemented with a CompleteMini protease inhibitor tablet (Roche, Indianopolis, IN, USA). 100ug of protein was loaded for SH-SY5Y lysates, and $20 \mu \mathrm{g}$ for NT2/D1 lysates. OCT4, SOX2 (Cell Signaling Technology, Toronto, ON, Canada) and Nanog (Cell Signaling Technology, Toronto, ON, Canada) antibodies were used at 1/1000 dilution. Secondary horseradish peroxidase conjugated antibodies (Jackson Immunoresearch, West Grove, PA, USA) were used at a dilution of 1/6000 and signal was detected with the Supersignal chemiluminescence detection system (Pierce Biotechnology, Rockford, Il, USA).

\section{Wound healing assay}

SH-SY5Y cells were seeded in a 48-well plate on glass cover slips and allowed to adhere overnight at a density of $10^{5}$ cells/well in $500 \mu \mathrm{l}$ culture medium in triplicate. Wells were marked with a straight black line on the bottom for orientation. At the time of $90 \%$ confluence, cell monolayers were scratched with a $200 \mu$ l pipette tip using the marker guide. Loosened non-adherent cells were washed off with medium. Fresh medium was added to the cultures with additions of AZ $(10 \mu \mathrm{M}, 20 \mu \mathrm{M}$, $40 \mu \mathrm{M})$ and MS-275 $(0.75 \mu \mathrm{M}, 1.5 \mu \mathrm{M}$ and $3 \mu \mathrm{M})$ and cultured for $48 \mathrm{~h}$. After the $48 \mathrm{~h}$ period cells were washed with PBS and fixed in $4 \%$ paraformaldehyde. After three washes in PBS, cells were stained with $1 \%$
Crystal violet in 20\% methanol. Phase contrast light microscopic images (10x original magnification) were taken at time points of 0,48 and $72 \mathrm{~h}$ of treatment. Migrated cells were counted manually to quantify numbers of cells migrated to wound area using NIH Image J program. Each experiment was conducted three times in triplicate and one representative assay is shown.

\section{Xenograft studies for determining the in vivo efficacy of AZ, MS-275, and AZ + MS-275 combination}

For the in vivo xenograft study, 4-6 weeks-old female NOD/SCID mice were obtained from the animal facility at The Hospital for Sick Children. The animal use protocols were approved by the Animal Care Committee, Sickkids Research Institute. Animals were treated per guidelines of Canadian Council on Animal Care (CCAC). Subcutaneous xenograft tumors were developed by injecting SH-SY5Y cells $\left(2 \times 10^{6}\right)$ into the inguinal fat pad of NOD/SCID mice. When tumor diameter reached $0.5 \mathrm{~cm}$, the mice were randomized into four groups ( 5 mice per group). The control and treatment groups received intraperitoneal injections of vehicle (PBS) or AZ $(40 \mathrm{mg} / \mathrm{kg})$, MS-275 $(20 \mathrm{mg} / \mathrm{kg})$ or the combination, respectively, every day for 2 weeks. Experiments were terminated when tumor sizes exceeded $2 \mathrm{~cm}^{3}$ in volume or animals showed signs of morbidity. Tumor diameters were measured on a daily basis until termination. The long (D) and short diameters (d) were measured with calipers. Tumor volume $\left(\mathrm{cm}^{3}\right)$ was calculated as $\mathrm{V}=0.5 \times \mathrm{D} \times \mathrm{d}^{2}$. After euthanizing the mice, tumors were resected, weighed and fixed in $10 \%$ neutral-buffered formalin at room temperature and processed for histopathology. For the in vivo serial heterotransplantation analysis, $2 \times 10^{6}$ untreated and pretreated AZ + MS-275 cells, manually and enzymatically dissociated from treated tumors, were injected subcutaneously to NOD/SCID mice. Growth rates were measured 2-3 times per week. On the 38th day, the animals were sacrificed, after which tumors were removed and weighed.

\section{Electron microscopic analysis}

Tumor fragments were fixed in $4 \%$ formaldehyde and $1 \%$ glutaraldehyde in phosphate buffer, $\mathrm{pH} 7.4$, and post fixed in $1 \%$ osmium tetroxide. Tumor tissues were then dehydrated in a graded series of acetone from 50 to $100 \%$ and subsequently infiltrated and embedded in Epon-Araldite epoxy resin. The processing steps from post fixation to polymerization of resin blocks were carried out in a microwave oven, Pelco BioWave 34770 (Pelco International, Clovis, CA, USA). Ultrathin sections were cut with a diamond knife on the Reichert Ultracut E (Leica Inc., Vienna, Austria). Uranyl acetate and lead citrate were used to stain the sections before 
being examined in the JEM-1011 (JEOL USA Inc., Peabody, MA, USA). Digital electron micrographs were acquired directly with a $1024 \times 1024$ pixels CCD camera system (AMT Corp., Danvers, MA, USA) attached to the ETM (1200 EX electron microscope).

\section{Immunohistochemistry}

Standard protocol was performed as described [17]. Immunohistochemistry (IHC) was performed on paraffin sections where slides underwent a series of deparaffinization and rehydration washes which were further processed for antigen retrieval and blockage of endogenous peroxidase activity. Sections were then incubated with secondary antibody broad-spectrum poly horseradish peroxidase, and incubation with DAB. The percentage of positive cells was calculated by using the formula [X (6 low power fields of positive staining)/ $\mathrm{Y}$ (total count per 6 fields $) \times 100]$. The level of IHC of the positive cells was also examined by ImageJ64 software.

\section{Terminal deoxynucleotidyl transferase dUTP nick end labelling (TUNEL) analysis}

The TUNEL assay was performed on $5 \mu \mathrm{m}$ sections prepared from formalin-fixed, paraffin-embedded xenografts, using the In Situ Cell Death Detection Kit
(Roche, Indianopolis, IN, USA) and the protocol suggested by the manufacturer, except that the positive control was treated with 500 units/ml DNaseI (Roche, Indianopolis, IN, USA) before adding the TUNEL reaction buffer. The peroxidase reaction was carried out with stable DAB solution (Invitrogen, Grand Island, NY, USA). Finally slides were counterstained with haematoxylin and examined under light microscopy.

\section{Statistical analyses}

The data are presented as mean +/- SD. Statistical analysis of variance was run based on triplicate experiments and performed with Graphpad Prism 5.0 software (Hearne Scientific Software, Chicago, IL, USA) using 2-tailed Student's $t$-test or 2-tailed paired $t$-test. Asterisks denote significance $\left({ }^{*}\right) p \leq 0.05 ;{ }^{(* *)} p \leq 0.01$; $(* * *) p \leq 0.001$. Coefficient of Drug Interaction (CDI) was used for the assessment of drug interaction (antagonistic, synergistic and additive). CDI was calculated by formula $A B / A x B$; where $A B, A$ and $B$ are the cytotoxicity ratio of the combination, $\mathrm{AZ}$ single agent and MS-275 single agent, respectively. Cytotoxicity ratio at a certain drug concentration is the ratio of $\%$ viability of cells at that concentration to \% viability of untreated cells. CDI equal to $1,<1$ and $>1$ is
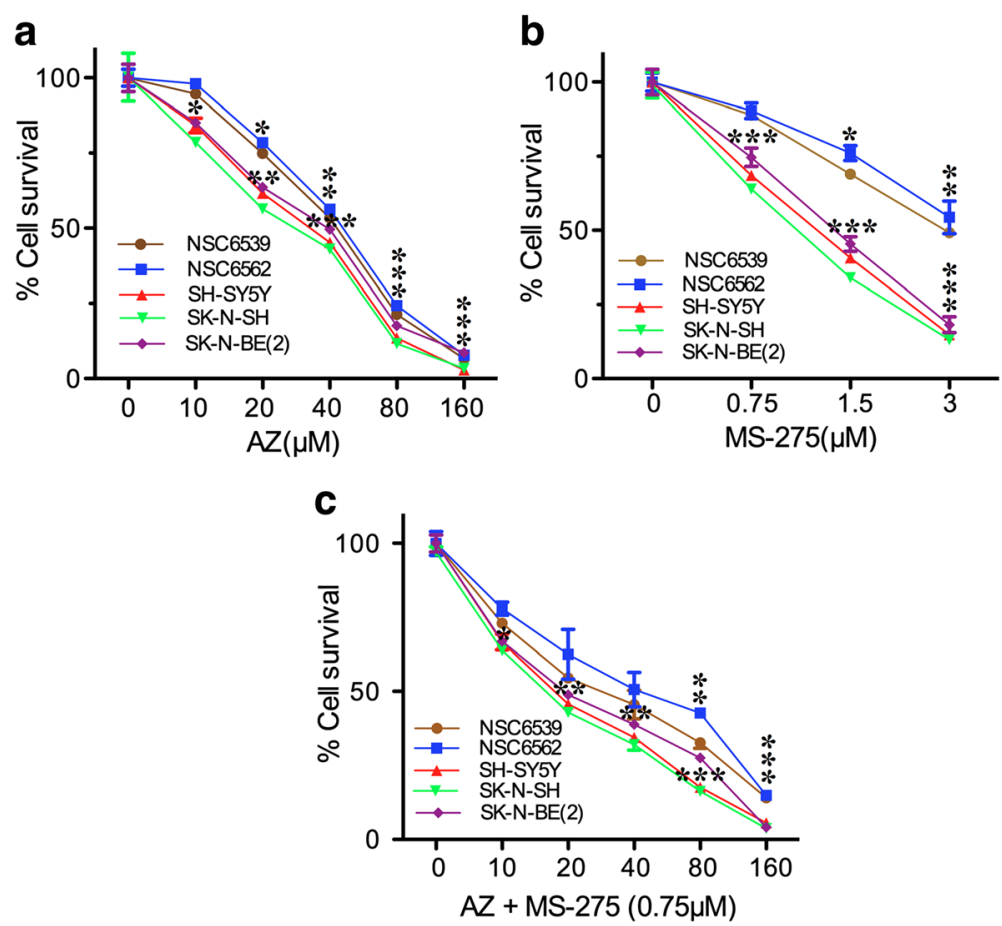

Fig. 1 AZ and/or MS-275 treatments produced a dose-dependent reduction in NB cells. a-c present graphic and tabulated evidence for the dose response. Doses were AZ(0-160 $\mu \mathrm{M})$, MS-275(0-3 $\mu \mathrm{M})$ and AZ + MS-275(0-160 $\mu \mathrm{M}+0.75 \mu \mathrm{M})$ for $48 \mathrm{~h}$ treatment of NSC6539, NSC6562, SH-SY5Y, SK-N-SH and SK-N-BE(2) cells compared to the untreated group. The greatest decrease in IC50 was observed for AZ + MS-275 combination as follow: SH-SY5Y $=17.5 \mu \mathrm{M}$, SK-N-SH $=16.5 \mu \mathrm{M}$ and SK-N-BE(2) $=19.2 \mu \mathrm{M}$ 
Table 1 Percentage of cell viability values

\begin{tabular}{|c|c|c|c|c|}
\hline Cell line & Treatment modality & Concentration $(\mu \mathrm{M})$ & Reduction in cell viability (\%) & $p$ value \\
\hline \multirow[t]{9}{*}{ NSC6539 } & \multirow[t]{3}{*}{$A Z$} & 10 & $6 \pm 0.67$ & - \\
\hline & & 20 & $26 \pm 0.87$ & $p<0.05$ \\
\hline & & 40 & $47 \pm 0.07$ & $p<0.01$ \\
\hline & \multirow[t]{3}{*}{ MS-275 } & 0.75 & $12 \pm 0.85$ & - \\
\hline & & 1.5 & $32 \pm 0.97$ & $p<0.05$ \\
\hline & & 3 & $51 \pm 0.23$ & $p<0.01$ \\
\hline & \multirow[t]{3}{*}{$A Z+M S-275$} & $10+0.75$ & $28 \pm 0.95$ & - \\
\hline & & $20+0.75$ & $46 \pm 0.56$ & $p<0.05$ \\
\hline & & $40+0.75$ & $55 \pm 0.50$ & $p<0.01$ \\
\hline \multirow[t]{9}{*}{ NSC6562 } & \multirow[t]{3}{*}{$A Z$} & 10 & $2 \pm 0.07$ & - \\
\hline & & 20 & $22 \pm 0.47$ & $p<0.05$ \\
\hline & & 40 & $45 \pm 0.67$ & $p<0.01$ \\
\hline & \multirow[t]{3}{*}{ MS-275 } & 0.75 & $10 \pm 0.34$ & - \\
\hline & & 1.5 & $24 \pm 0.08$ & $p<0.05$ \\
\hline & & 3 & $46 \pm 0.39$ & $p<0.01$ \\
\hline & \multirow[t]{3}{*}{$A Z+M S-275$} & $10+0.75$ & $23 \pm 0.86$ & - \\
\hline & & $20+0.75$ & $38 \pm 0.50$ & $p<0.05$ \\
\hline & & $40+0.75$ & $50 \pm 0.61$ & $p<0.01$ \\
\hline \multirow[t]{9}{*}{ SH-SY5Y } & \multirow[t]{3}{*}{$A Z$} & 10 & $16 \pm 0.20$ & $p<0.05$ \\
\hline & & 20 & $39 \pm 0.64$ & $p<0.01$ \\
\hline & & 40 & $35 \pm 0.58$ & $p<0.001$ \\
\hline & \multirow[t]{3}{*}{ MS-275 } & 0.75 & $32 \pm 0.55$ & $p<0.001$ \\
\hline & & 1.5 & $60 \pm 0.69$ & $p<0.001$ \\
\hline & & 3 & $86 \pm 0.78$ & $p<0.001$ \\
\hline & \multirow[t]{3}{*}{$A Z+M S-275$} & $10+0.75$ & $35 \pm 0.85$ & $p<0.01$ \\
\hline & & $20+0.75$ & $55 \pm 0.86$ & $p<0.001$ \\
\hline & & $40+0.75$ & $64 \pm 0.78$ & $p<0.001$ \\
\hline \multirow[t]{9}{*}{ SK-N-SH } & \multirow[t]{3}{*}{$A Z$} & 10 & $22 \pm 0.59$ & $p<0.01$ \\
\hline & & 20 & $34 \pm 0.42$ & $p<0.01$ \\
\hline & & 40 & $61 \pm 0.03$ & $p<0.001$ \\
\hline & \multirow[t]{3}{*}{ MS-275 } & 0.75 & $37 \pm 0.99$ & $p<0.001$ \\
\hline & & 1.5 & $66 \pm 0.03$ & $p<0.001$ \\
\hline & & 3 & $87 \pm 0.19$ & $p<0.001$ \\
\hline & \multirow[t]{3}{*}{$A Z+M S-275$} & $10+0.75$ & $37 \pm 0.85$ & $p<0.01$ \\
\hline & & $20+0.75$ & $58 \pm 0.86$ & $p<0.001$ \\
\hline & & $40+0.75$ & $69 \pm 0.95$ & $p<0.001$ \\
\hline \multirow[t]{9}{*}{ SK-N-BE(2) } & \multirow[t]{3}{*}{$A Z$} & 10 & $15 \pm 0.01$ & $p<0.01$ \\
\hline & & 20 & $37 \pm 0.61$ & $p<0.01$ \\
\hline & & 40 & $61 \pm 0.58$ & $p<0.001$ \\
\hline & \multirow[t]{3}{*}{ MS-275 } & 0.75 & $26 \pm 0.69$ & $p<0.001$ \\
\hline & & 1.5 & $55 \pm 0.38$ & $p<0.001$ \\
\hline & & 3 & $82 \pm 0.21$ & $p<0.001$ \\
\hline & \multirow[t]{3}{*}{$A Z+M S-275$} & $10+0.75$ & $34 \pm 0.88$ & $p<0.01$ \\
\hline & & $20+0.75$ & $52 \pm 0.88$ & $p<0.001$ \\
\hline & & $40+0.75$ & $62 \pm 0.86$ & $p<0.001$ \\
\hline
\end{tabular}


considered as additive, synergistic and antagonistic, respectively.

\section{Results}

$A Z$, MS-275 and AZ + MS-275 treatments inhibit growth of NB SH-SY5Y cells

To determine the effect of AZ, MS-275 and AZ + MS275 treatments on the growth of NB SH-SY5Y, SK-N-SH and SK-N-BE(2) cells, we used the AlamarBlue and trypan blue assays. As reference normal controls, we included the neuronal stem cell strains, NSC6539 and NSC6562, which represent neural lineage derived stem cells albeit from the central nervous system [25]. We chose clinically acceptable concentration ranges for AZ $(0-160 \mu \mathrm{M})[17,26]$ and MS-275 $(0-3 \mu \mathrm{M})$ [7-9, 27]. It should be noted that AlamarBlue also indicates effects on oxidative phosphorylation as it is a substrate for the last step in oxidative phosphorylation. Thus it can also reflect metabolic mitochondrial effects.

Figure 1a-c shows that both AZ and MS-275 had a more moderate concentration-dependent inhibitory effect on neuronal stem cells while the effects of MS-275 and the AZ + MS-275 combination were significantly enhanced on all three tumor lines. The reduction in cell viability and IC50 values of NSC6539, NSC6562, SHSY5Y, SK-N-SH and SK-N-BE(2) by AZ, MS-275, and $\mathrm{AZ}+\mathrm{MS}-275$ (48 h) shows the highest percent reduction with AZ + MS-275 in achievable plasma concentration (Tables 1 and 2). A significant difference in IC50 values for SH-SY5Y, SK-N-SH and SK-N-BE(2), indicates the potentiation of MS-275 effect by AZ. Interestingly, CDI analysis for the combination of AZ and MS-275 on different cell lines reveal that the combination is antagonistic at all concentrations on NSC6539 cells $(\mathrm{CDI}=$ 1.14-1.42) and additive on NSC6562 cells at concentrations above $20 \mu \mathrm{M} \mathrm{AZ} \mathrm{(CDI=1).} \mathrm{On} \mathrm{NB} \mathrm{cell} \mathrm{lines}(\mathrm{SH}-$ SY5Y, SK-N-SH and SK-N-BE(2)) the combination was found to be additive at $40 \mu \mathrm{M}$ and $80 \mu \mathrm{M}$ of $\mathrm{AZ}(\mathrm{CDI}=1)$ and synergistic at $160 \mu \mathrm{M}$ of $\mathrm{AZ}(\mathrm{CDI}<1)$. Since SHSY5Y showed moderate resistance to AZ and/or MS-275,

Table 2 Percentage of IC50 values

\begin{tabular}{llll}
\hline Cell & IC50 $(\mu \mathrm{M})$ & & \\
\cline { 2 - 4 } & $\mathrm{AZ}$ & $\mathrm{MS}-275$ & $\mathrm{AZ}+\mathrm{MS}-275$ \\
\hline NSC6539 & 53 & 2.8 & 23.5 \\
NSC6562 & 56 & 3 & 35 \\
SH-SY5Y & 45 & 1.23 & 17.5 \\
SK-N-SH & 42 & 1 & 16.5 \\
SK-N-BE(2) & 49 & 1.48 & 19.2 \\
\hline
\end{tabular}

Table 2 shows percentage of NSC6539, NSC6562, SH-SY5Y, SK-N-SH and SK-N$\mathrm{BE}(2)$ by $\mathrm{AZ}(0-160 \mu \mathrm{M}), \mathrm{MS}-275(0-3 \mu \mathrm{M})$, and AZ + MS-275 $(0-160 \mu \mathrm{M}+$ $0.75 \mu \mathrm{M})$ treatments $(48 \mathrm{~h})$ average concentration-response and IC50 compared to the other two NB cell lines, we chose to focus on $\mathrm{SH}$ SY5Y cell line for the rest of the study. The AlamarBlue assay results also raised the question of effects on apoptosis and cell cycle as a measure of possible growth arrest and/or toxicity.

We characterized the effect on apoptosis and cell cycle using a propidium iodide (PI) based FACS analysis. Using a dose less than the IC50 dose, AZ $(40 \mu \mathrm{M}$ vs. $45 \mu \mathrm{M}), \mathrm{MS}-275(1.5 \mu \mathrm{M}$ vs. $2.36 \mu \mathrm{M})$ and $\mathrm{AZ}+\mathrm{MS}$ $275(40 \mu \mathrm{M}+0.75 \mu \mathrm{M})$ it was found that AZ, MS-275 and AZ + MS-275 treatments increase entry of SH-SY5Y cells into SubG0-phase $(0.6 \%, \% 57$ and \%61) with decrease into S-phase (13\%, 9\% and 4\%) and G2/M-phase (6\%, $2 \%$ and $3 \%)$, significantly following a $48 \mathrm{~h}$ dosage of $\mathrm{AZ}(40 \mu \mathrm{M}), \mathrm{MS}-275(1.5 \mu \mathrm{M})$ and AZ + MS-275 $(40 \mu \mathrm{M}$ $+0.75 \mu \mathrm{M}$ ), respectively (Fig. 2a-b). In addition, western blot analysis of cell cycle inhibitor, p21, shows that MS275 and AZ + MS-275 treatments (48 h) cause of 4.5 and 5.5 induction of p21 $(p<0.01)$ of SH-SY5Y cells compare to control, respectively (Fig. 2c-d). Results would suggest that AZ, MS-275 and AZ + MS-275 treatments are inducing apoptosis and preventing entry into $\mathrm{S}$ and G2/M-phases. This was further characterized by in-cell western and western blot analysis of cell cycle checkpoints, demonstrating a 2.5 fold induction of p16 $(85 \% \pm 0.19 \% ; p<0.001)$, a 1.97 fold induction of $\mathrm{p} 21$ $(50 \% \pm 0.64 \% ; p<0.001)$, a 1.48 fold induction of $\mathrm{p} 27$ $(34 \% \pm 0.31 \% ; p<0.05)$, cyclin dependent kinase inhibitors (Cdki), and downregulation of CDK4 $(33 \% \pm 0.15 \%$; $p<0.01)$ and cyclin D1 $(31 \% \pm 0.35 \% ; p<0.001)$ following a $48 \mathrm{~h}$ dosage of $1.5 \mu \mathrm{M}$ MS-275, respectively (Fig. 2e-f). These results were confirmed by western blot analysis (Fig. 2 g-h). Furthermore, western blot analysis of the expression of the Ki67 proliferative marker showed a down regulation of Ki67 (Fig. 2 g-h). Ki67 is expressed at all points during the cell cycle, except in G0. It should be noted that inductions of Cdki p21 occurred at the lower concentration of MS-275 but decreased somewhat at the higher concentrations suggesting a more complex epigenetic regulatory mechanism. Overall Cdki inductions varied except for p16. We also conducted a PI cell cycle analysis to determine the percentage of sub-G1 cell.

Since cell death due to mechanical damage is also accounted for in sub-G1 cell analysis, we also assessed Annexin/7-AAD and cleaved-caspase 3 expressions by FACs. Annexin stains cells in the early stage of apoptosis, while positive stain for 7-AAD indicates loss of membrane integrity. Cells at end stage of apoptosis are characterized by double staining for Annexin and 7AAD. The results of FACs analysis demonstrated that MS-275 induces both early (10.7\%) and late stage apoptosis $(7.66 \%)$. The parallel assay with a clinically used 


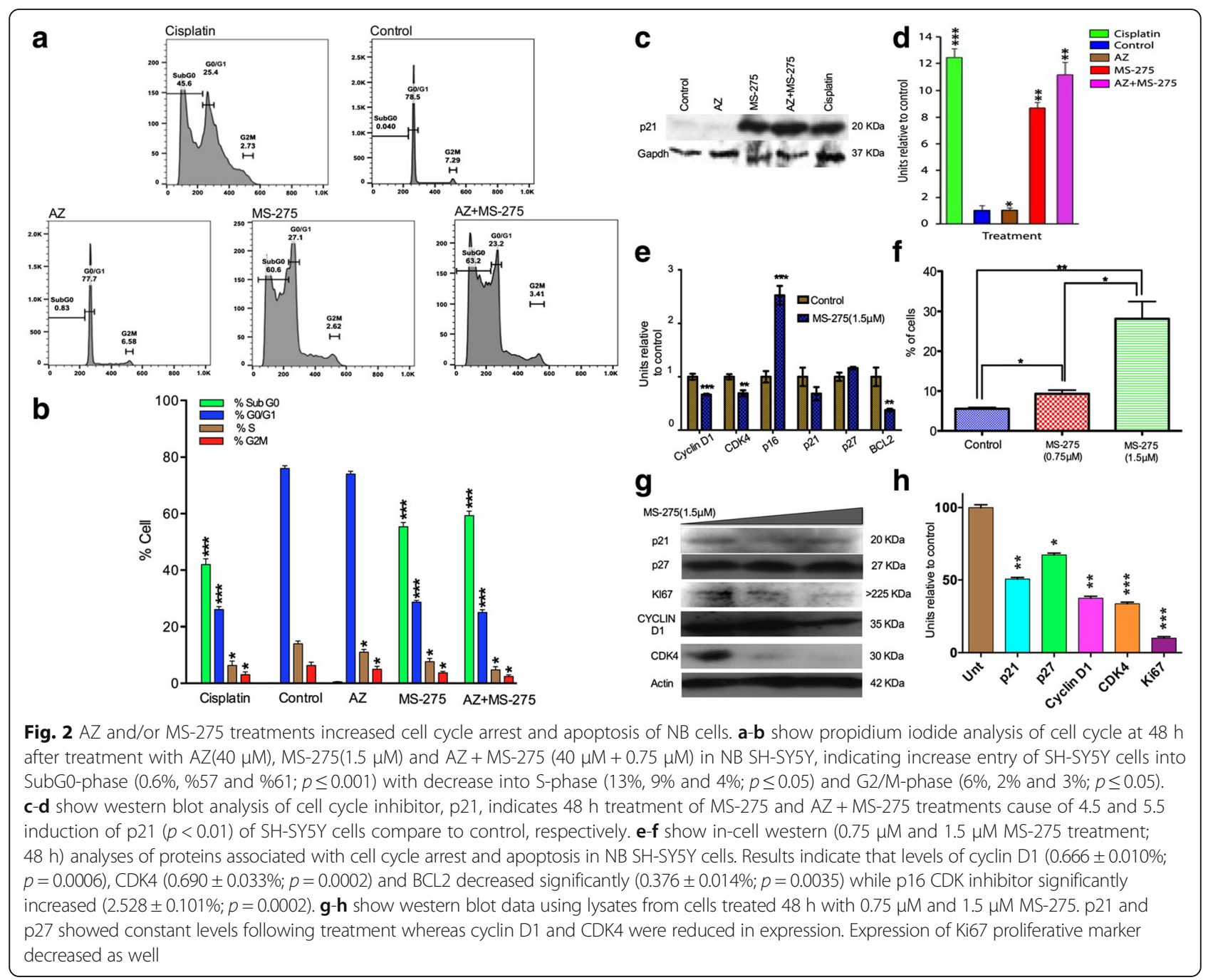

chemotherapeutic $1 \mu \mathrm{M}$ Etoposide (the IC50 dose) showed $2.51 \%$ and $8.58 \%$ induction of early and late stage apoptosis, respectively (Fig. 3a and Table 3). In addition, using the apoptotic indicator, cleaved caspase 3, $0.75 \mu \mathrm{M}$ and $1.5 \mu \mathrm{M}$ MS-275 after $48 \mathrm{~h}$ treatment yielded significantly $1 \%$ and $3 \%$ expression of cleavedcaspase 3 , respectively $(p=0.0003$ and $p<0.0001$ respectively as compared to control and $p=0.0001$ when comparing doses) (Fig. 3b-c). The pro-apoptotic effect of MS-275 was further investigated by western blot analysis of BCL2 and BAX expression. The results demonstrated that BCL2/BAX ratio is reduced (19.6\% of control) by $1.5 \mu \mathrm{M}$ MS-275 treatment (48 h);(Fig. 3d), indicating a potent apoptotic effect. MS-275 increases the expression of apoptotic protein BAX, hence decreasing the BCL2/BAX ratio, and coordinate with decrease in survival. Western blot analysis also demonstrated that survivin, a potent inhibitor of apoptosis, is reduced in expression following MS-275 treatment (Fig. 3e). Here
NT2/D1 is a neuronal subclone of the teratomas NT2 cell line used in comparison, and as it is more stem cell like.

\section{AZ, MS-275 and AZ + MS-275 treatments reduced migration capacity in NB SH-SY5Y cells}

Previous studies had shown that both AZ and MS-275 reduce migration capacity in bladder and liver cancer cells $[27,28]$. In the current study, we show the reduction of migration capacity in AZ $(40 \mu \mathrm{M})$, MS-275 $(1.5 \mu \mathrm{M})$ and $\mathrm{AZ}+\mathrm{MS}-275(40 \mu \mathrm{M}+0.75 \mu \mathrm{M})$ treated NB SH-SY5Y cells in Table 4. In Fig. 4a it is evident that $\mathrm{AZ}$ alone has an obvious inhibitory effect, and greatly enhanced by MS-275 at $48 \mathrm{~h}$. The difference between MS-275 alone and the combo treatment was statistically significant $(p<0.001)$ at both $48 \mathrm{~h}$ and $72 \mathrm{~h}$. AZ therefore enhances the inhibitory effect of MS-275 on SH-SY5Y cell migration capacity (Fig. 4a-b). In this assay the cytotoxicity of the agents is demonstrated overtly 

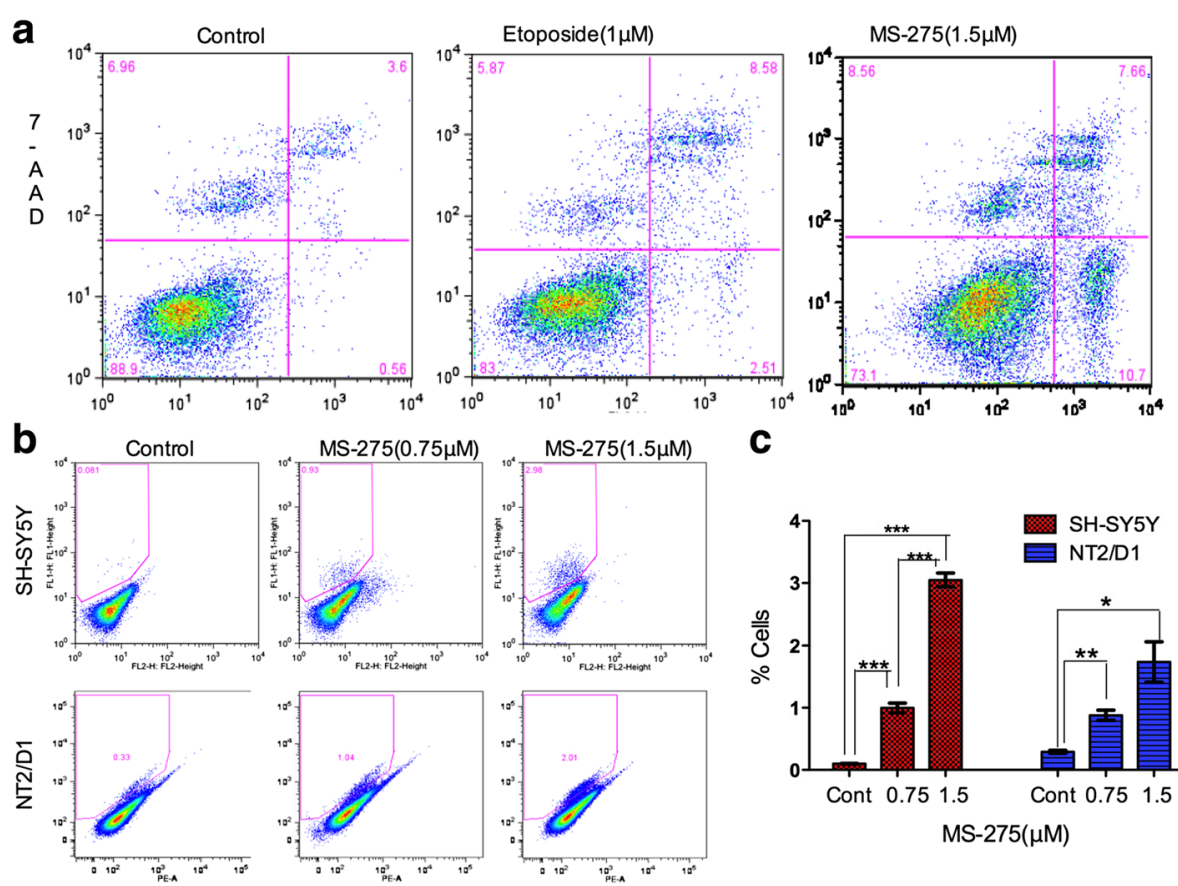

C
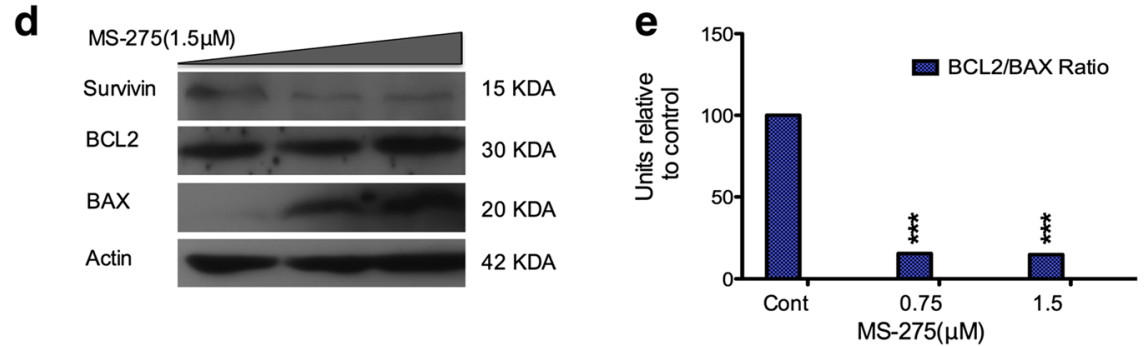

Fig. 3 a-b show the results of FACs analysis for 7-AAD and Annexin staining. Results demonstrate that compared to etoposide, MS-275 induces entry into early and late stage of apoptosis in $10.7 \%$ versus $2.51 \%$ and $7.66 \%$ versus $8.58 \%$ of cells, respectively. c show cleaved caspase 3 expression after $48 \mathrm{~h}$ treatment with $0.75 \mu \mathrm{M}$ and $1.5 \mu \mathrm{M}$ MS-275 that yielded $1 \%$ and $3 \%$ expression, respectively $(p=0.0003$ and $p<0.0001$, respectively as compared to control and $p=0.0001$ when comparing doses). $\mathbf{d}$-e show increased expression of apoptotic protein BAX and decreased BCL2/BAX ratio with coordinate decrease in survival following $0.75 \mu \mathrm{M}$ and $1.5 \mu \mathrm{M}$ MS-275 treatment to $15.59 \%$ and $14.86 \%$ of control. In addition, survivin expression reduced following $0.75 \mu \mathrm{M}$ and $1.5 \mu \mathrm{M}$ MS-275 treatment to $7.8 \%$ and $11 \%$, respectively

because of the initial cell confluence and may predict subsequent in vivo effects.

\section{AZ significantly potentiates the inhibitory effect of MS-275 on tumorigenesis in NB SH-SY5Y xenografts} A concentration of $24.5 \mathrm{mg} / \mathrm{kg} \mathrm{MS}-275$ reduced growth of NB KCNR cell line as orthotopic xenografts [8]. A 14day treatment protocol with $40 \mathrm{mg} / \mathrm{kg} \mathrm{AZ}$ and/or
$20 \mathrm{mg} / \mathrm{kg}$ MS-275 was devised based on the observed IC50 results and previously used safe doses in other preclinical studies $[8,29]$. The inhibition of tumor volume is presented in Table 5. Figure 5a grossly shows a dramatic reduction in tumor growth and volume after MS$275(20 \mathrm{mg} / \mathrm{kg})$ and significantly greater when AZ $(40 \mathrm{mg} / \mathrm{kg})$ was added to the treatment. Figure $5 \mathrm{~b}$ shows the changes in histology suggesting phenotypic alterations

Table 3 Percentage of apoptosis values

\begin{tabular}{lllll}
\hline & Unstained (Lower left) & Annexin (Lower right) & 7-AAD (Upper left) & Annexin 7-AAD (Upper right) \\
\hline Control & 90 & 0.6 & 6.80 & 3.9 \\
Etoposide $(1 \mu \mathrm{M})$ & 85 & 2.57 & 5.90 & 8.68 \\
MS-275 $(1.5 \mu \mathrm{M})$ & 72.18 & 10.11 & 8.60 & 7.06 \\
\hline
\end{tabular}

Table 3 shows the parallel assay with a clinically used chemotherapeutic Etoposide $(1 \mu \mathrm{M}) ;(2.51 \%$ and $8.58 \%)$ and MS-275 (1.5 $\mu \mathrm{M}) ;(10.7 \%$ and $7.66 \%)$ showed induction of early and late stage apoptosis, respectively 
Table 4 Percentage of cell migration capacity values

\begin{tabular}{llll}
\hline Time & \multicolumn{1}{l}{ Control } & \multicolumn{1}{c}{$48 \mathrm{~h}$} & $72 \mathrm{~h}$ \\
Treatment & \% Cell migration & capacity & \\
\hline Untreated & 94 & 95.33 & 96.98 \\
AZ & 93.66 & 90.3 & 85.87 \\
& - & - & $p<0.01$ \\
MS-275 & 94 & 42.33 & 38.56 \\
& & $p<0.001$ & $p<0.001$ \\
AZ + MS-275 & 95 & 37 & 26 \\
& & $p<0.001$ & $p<0.001$ \\
\hline
\end{tabular}

Table 4 shows percentage of cell migration capacity values of SH-SY5Y by AZ $(40 \mu \mathrm{M}), \mathrm{MS}-275(0.75 \mu \mathrm{M})$ and $\mathrm{AZ}+\mathrm{MS}-275(40 \mu \mathrm{M}+0.75 \mu \mathrm{M})$ treatments (48 $\mathrm{h}$ and $72 \mathrm{~h}$ )

while Fig. $5 \mathrm{c}$ and d graphically reflect large reductions of volumes and weights, over the 14 days treatment period. The extirpated tumors also revealed grossly that both MS-275 and AZ + MS-275 markedly reduced the hematogeneous appearance of the tumors suggesting significant loss of vascularization (Fig. 5a-b). The significant reductions in tumor growth and weight were greatest with AZ + MS-275 (Table 5). The significant anti-tumor growth potentiation effect of AZ on MS275 suggested an additive effect for this combination. IHC results revealed a possible explanation for the dramatic reduction in tumor volumes in that there was a strong inhibition of angiogenesis as revealed with staining for the angiogenesis marker (CD31) (Fig. 5e). Compared to the untreated group, expression of the CD31 was most significantly reduced with the combination $\mathrm{AZ}+\mathrm{SFN}$ (Table 5; Fig. 5f).

\section{$A Z, M S-275$ and the AZ + MS-275 treatments induce apoptosis in NB SH-SY5Y xenograft cells}

The initial histopathological assessment of the residual tumors (Fig. 5a-e) revealed reductions in cell density and size, presence of pyknotic nuclei and reduced nuclear size, most prominently in the case of AZ + MS-275. This suggested that apoptosis could account for cell loss. To further confirm the histological changes, we performed electron microscopy on the tumor xenografts. Ultrastructural analysis revealed cells with degradative cytoplasmic changes $[8,30,31]$ and nuclear fragmentation (pyknotic cells) indicative of apoptosis in SH-SY5Y xenografts. AZ + MS-275 treated cells had the highest number of pyknotic cells (Table 6; Fig. 6a-b), further supported the histological finding that AZ potentiated the apoptotic effect of MS-275. Next, we assessed apoptosis with the TUNEL assay on the xenografts (Table 6). We found that AZ+MS-275 treated cells had the highest percent TUNEL positive cells (Fig. 6c-d), and significantly greater than MS-275 alone. To further confirm the apoptotic process, we performed IHC to study the effect of AZ, MS-275 and AZ + MS-275 treatments on expression of the apoptotic marker (cleaved PARP) in the SH-SY5Y xenografts. Compared to the untreated group, expression of the apoptotic marker (cleaved PARP) was significantly induced, versus untreated controls (Table 6; Fig. 6e-f). Thus, AZ showed an overt potentiation of the anti-tumor effect of MS275 in the SH-SY5Y xenografts.

$A Z, M S-275$ and $A Z+M S-275$ reduce expression of mitotic and proliferative markers in NB SH-SY5Y xenografts

The results from the apoptosis assessment of treated xenografts suggested strong effects on tumor cell proliferation. We therefore performed IHC to study the effect of AZ, MS-275 and AZ + MS-275 treatments on expression of mitotic (phosphohistone-H3; pHH3) and proliferation (Ki-67) markers in the SH-SY5Y xenografts. Compared to the untreated group, expression of the mitotic marker (pHH3) was moderately reduced after $\mathrm{AZ}$ treatment alone, significantly after MS-275 treatment and further enhanced with the combination AZ + MS-275 (Table 7; Fig. 7a-b). In a similar manner expression of the proliferative marker, Ki67 was significantly reduced by all treatments and the most by AZ + MS-275 (Table 7; Fig. 7c-d). Thus, the large reductions in tumor growth produced by MS-275 and the AZ + MS-275 combination are additionally reflected in significant reductions in mitosis and proliferation paralleled by increased apoptosis. It is noteworthy that the potent inhibitory effect of AZ alone was revealed using these markers, and potentiation of MS-275 was further confirmed.

\section{AZ and/or MS-275 treatment reduced expression of HIF1-a and CAIX in NB SH-SY5Y xenograft}

Given the remarkable reductions in vascularization it might be surmised that the tumors would experience enhanced hypoxia under the treatments and thereby increased hypoxia induced gene expression. However, we performed IHC on the xenografts and did observe that control untreated tumors significantly expressed HIF1- $\alpha$ and its downstream target CAIX (Table 7; Fig. 8a-d). We further found that the number of HIF1- $\alpha$ positive cells decreased significantly after all treatments and markedly after AZ + MS-275 (Table 8; Fig. 8a and b). Additionally, a markedly enhanced reduction in CAIX expression (membrane localization) after AZ + MS-275 (Table 8; Fig. $8 \mathrm{c}$ and d) paralleled that of HIF1- $\alpha$. The major reduction in CAIX staining after AZ + MS-275 may reflect much more than a loss of viable cells supporting the concept of $\mathrm{AZ}$ potentiation of the epigenetic alterations in expression. 


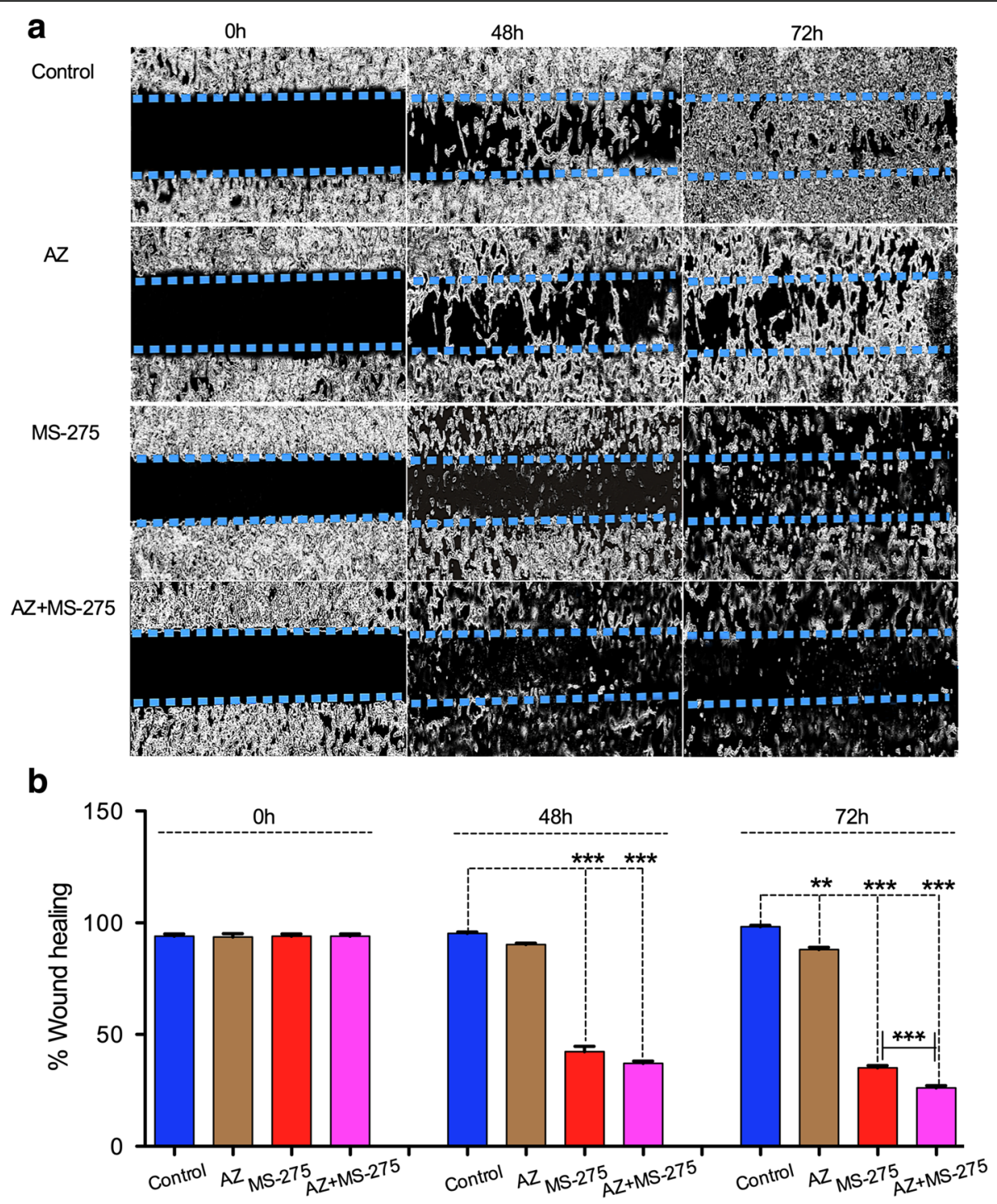

Fig. 4 AZ and/or MS-275 treatments decreased migration capacity of NB cells. a-b represent the wound healing assay for AZ (40 $\mu$ M), MS-275 $(1.5 \mu \mathrm{M})$ and $\mathrm{AZ}+\mathrm{MS}-275(40 \mu \mathrm{M}+0.75 \mu \mathrm{M})$ treatment compared to untreated group in SH-SY5Y cells. AZ caused a $10 \pm 0.35 \%(p=0.025,48 \mathrm{~h})$ and $12 \pm 0.85 \%(p<0.01,72 \mathrm{~h}$ ) inhibition while MS-275 caused a $42 \pm 0.13 \%(p<0.001,48 \mathrm{~h})$ and $65 \pm 0.30 \%(p<0.001,72 \mathrm{~h})$ inhibition in migration. The AZ + MS-275 combination significantly inhibited migration with a $63 \pm 0.37 \%(p<0.001,48 \mathrm{~h})$ and $74 \pm 0.25 \%(p<0.001,72 \mathrm{~h})$ inhibition in migration ability

Table 5 Percentage of tumor volume, weight and expression of CD31 values

\begin{tabular}{lllll}
\hline Treatment modality & Concentration $(\mathrm{mg} / \mathrm{kg})$ & $\begin{array}{l}\text { \% Inhibition of tumor volume } \\
(p \text { value })\end{array}$ & $\begin{array}{l}\text { \% Reduction in tumor weight } \\
(p \text { value })\end{array}$ & $\begin{array}{l}\text { \% Expression of CD31 marker } \\
(p \text { value })\end{array}$ \\
\hline AZ & 40 & $13 \pm 0.29(p=0.009)$ & $29 \pm 0.2(p=0.193)$ & $87 \pm 0.98(p=0.006)$ \\
MS-275 & 20 & $43 \pm 0.50(p=0.001)$ & $83 \pm 0.74(p<0.001)$ & $48 \pm 0.94(p=0.008)$ \\
AZ + MS-275 & $40+20$ & $60 \pm 0.48(p=0.001)$ & $89.5 \pm 0.94(p<0.001)$ & $27 \pm 0.92(p<0.001)$ \\
\hline
\end{tabular}

Table 5 shows percentage of tumor volume and weight reduction and expression of CD31 values of SH-SY5Y tumors by AZ (40 mg/kg), MS-275 (20 mg/kg) and $\mathrm{AZ}+\mathrm{MS}-275(40+20 \mathrm{mg} / \mathrm{kg})$ treatments $(14 \mathrm{D})$ 
a

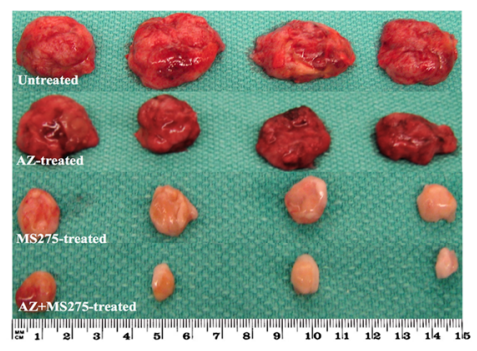

C
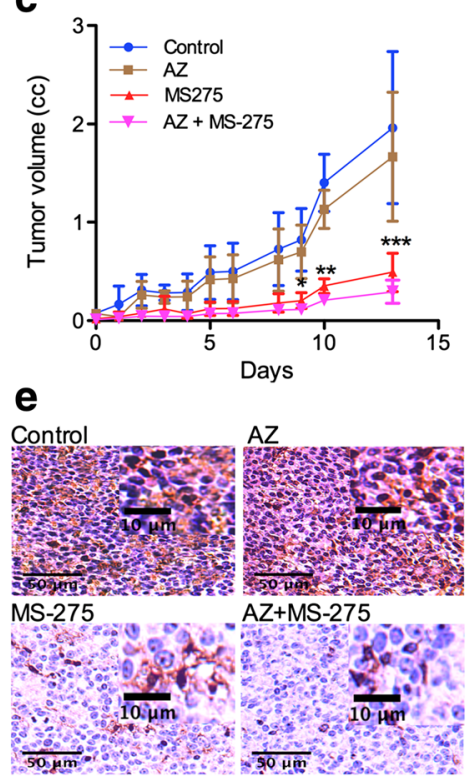

b

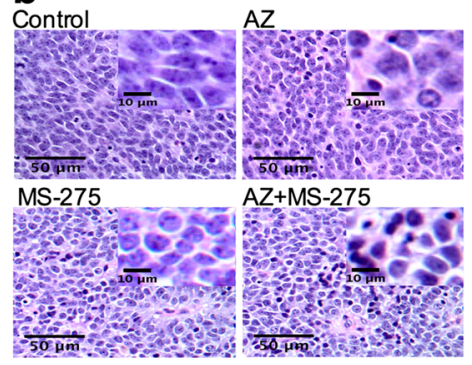

d

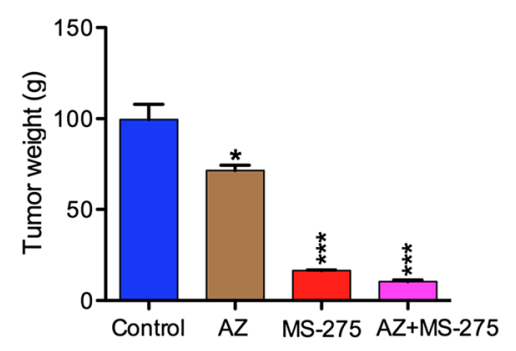

f

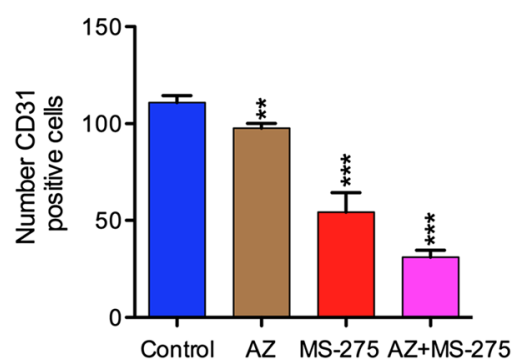

Fig. 5 AZ and/or MS-275 inhibited tumor growth of NB xenografts. a presents the gross morphology, b H\&E histology, c volume, $\mathbf{d}$ weight, e CD31 staining and $\mathbf{f}$ the percentage of CD31 positive cells after 14 days treatment with AZ and/or MS-275 compared to the untreated group in SH-SY5Y xenografts. AZ caused 13\% $0.29 \%$, MS-275 43\% $\pm 0.50 \%$ and AZ + MS- $27560 \% \pm 0.48 \%(p=0.0009)$ inhibition in tumor growth. Tumor weights were reduced by $29 \pm 0.2 \%(p=0.193)$ for AZ, $83 \% \pm 0.74 \%(p<0.001)$ for MS-275 and $89.5 \pm 0.49 \%(p<0.001)$ for AZ + MS 275 . AZ caused a $13 \% \pm 0.98 \%(p=0.006), M S-275$ a $52 \% \pm 0.0 .94 \%(p=0.0008)$ and $A Z+M S-275$ a $73 \% \pm 0.92 \%(p<0.0001)$ decrease in the number of CD31 positive cells compared to the control

\section{AZ + MS-275 treatment significantly reduces the in vivo} tumorigenic potential of NB SH-SY5Y xenograft cells The ultimate test for loss of tumorigenic potential is whether treatments abrogate formation of tumors, accomplished by conducting serial heterotransplantation. To test this, after the initial round of treatments with the most effective AZ + MS-275 combination we serially heterotransplanted a second set of $3 \times 10^{4}$ cells into NOD/SCID mice and in comparison to a similar number of untreated cells. We found that the combination of AZ + MS-275 caused a $69 \% \pm 0.84 \%(p=0.0002)$ inhibition in resulting tumor volumes and weights $(81 \% \pm 0.78 \%$; $p=0.0001$ ) respectively after 38 days (Fig. 9a-d). Note however that only $3 / 5$ injections yielded any tumor

Table 6 Percentage of pyknotic, TUNEL and Cleaved PARP positive cells values

\begin{tabular}{llll}
\hline Treatment modality & \% Pyknotic cells $(p$ value $)$ & \% TUNEL positive cells $(p$ value $)$ & \% Cleaved PARP positive cells $(p$ value $)$ \\
\hline AZ & $8 \pm 0.6(p<0.001)$ & $7 \pm 0.66(p=0.0015)$ & $12 \pm 0.7(p<0.01)$ \\
MS-275 & $36 \pm 0.45$ & $56 \pm 0.33(p<0.001)$ & $50 \pm 0.23(p<0.001)$ \\
AZ + MS-275 & $51 \pm 0.83(p<0.001)$ & $82 \pm 0.76(p<0.001)$ & $69 \pm 0.35(p<0.001)$ \\
\hline
\end{tabular}

Table 6 shows the percentage of pyknotic, TUNEL and Cleaved PARP positive cells values of SH-SY5Y tumors by AZ (40 mg/kg), MS-275 (20 mg/kg) and AZ + MS-275 $(40+20 \mathrm{mg} / \mathrm{kg})$ treatments (14D) 


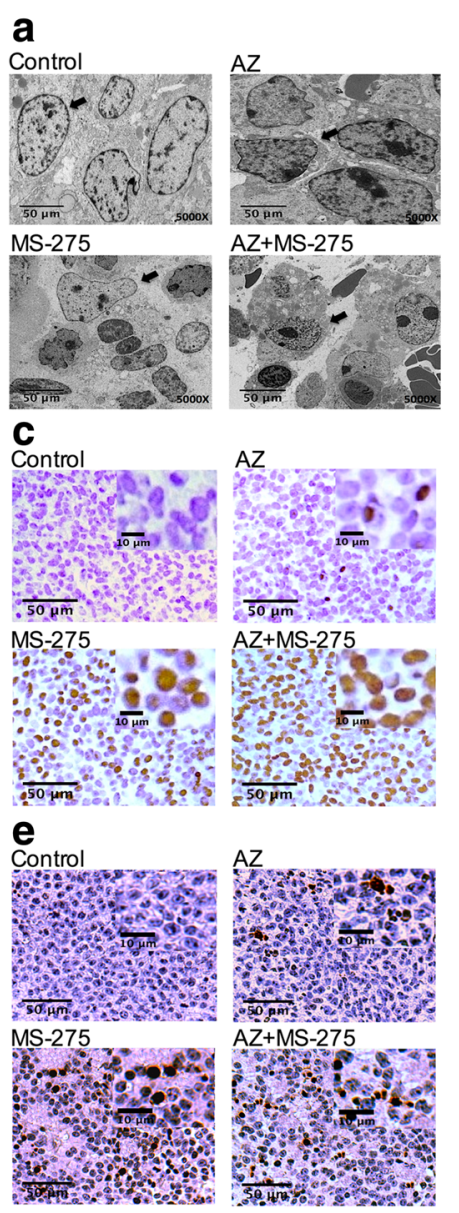

b

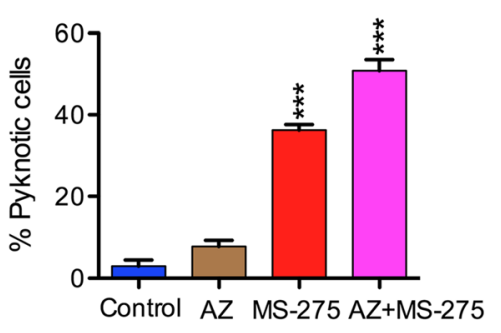

d

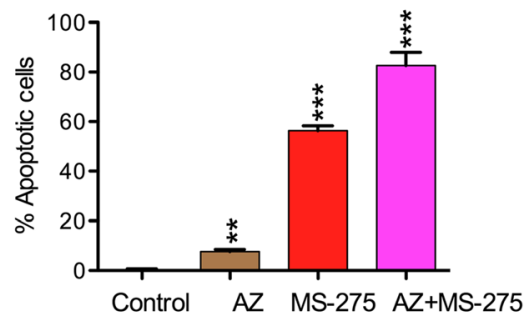

$\mathbf{f}$

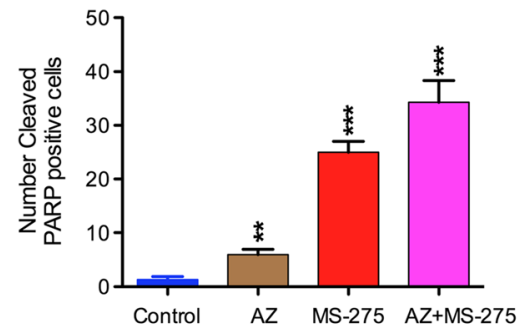

Fig. 6 AZ and/or MS-275 treatments increase the apoptotic TUNEL index in NB xenografts. a-b present ultrastructural details [x5000, cytoplasmic (arrow)] including the percentage of pyknotic cells. c-d present results from the TUNEL assay ( $\times 20$ and $\times 40$ ) for detection of apoptotic cells (arrow) and the number of apoptotic positive cells after 14 days treatment with AZ, MS-275 and AZ + MS-275 compared to untreated group in SH-SY5Y xenografts. The number of TUNEL positive cells increased modestly after treatment with AZ $(7 \pm 0.66 \% ; p=0.0015)$, moderately after MS-275 $(56 \pm 0.33 \% ; p<0.001)$ and significantly after AZ + MS-275 (82 $\pm 76 \% ; p<0.001)$ compared to the untreated group. e-f present the expression of the apoptotic marker (cleaved PARP) that was significantly induced by AZ (12\% $\pm 0.16 \% ; p=0.001)$, MS- $275(63 \% \pm 0.33 \% ; p=0.0001)$ and further by AZ + MS-275 (78\% $\pm 0.09 \% ; p=0.0001)$

mass. A marked phenotypic alteration in morphological appearance (Fig. 9b) resembled the treated tumors in Fig. 5a-e. These results suggest that the $\mathrm{AZ}+\mathrm{MS}-275$ combination might permanently alter cell phenotype and affect the presumptive CSCs in the tumor.

\section{AZ, MS-275 and AZ + MS-275 treatment affects stem cell marker expression in NB SH-SY5Y xenograft cells}

Our serial heterotransplantation results suggested that the CSC fraction could be targeted by a potentiated effect of AZ + MS-275. In parallel studies, we had examined the effect of MS-275 on another MYCN amplified NB cell line,

Table 7 Percentage of pHH3 and Ki67 positive cells values

\begin{tabular}{lll}
\hline Treatment modality & $\begin{array}{l}\text { \% Expression of } \mathrm{pHH3} \text { positive cells } \\
(p \text { value })\end{array}$ & $\begin{array}{l}\text { \% Expression of Ki67 positive cells } \\
(p \text { value })\end{array}$ \\
\hline AZ & $58 \pm 0.66(p<0.05)$ & $61 \pm 0.77(p=0.01)$ \\
MS-275 & $22 \pm 0.11(p<0.01)$ & $29 \pm 0.42(p<0.001)$ \\
AZ + MS-275 & $6 \pm 0.73(p<0.001)$ & $16 \pm 0.85(p<0.001)$ \\
\hline
\end{tabular}

Table 7 shows percentage of pHH3 and Ki67 positive cells values of SH-SY5Y tumors by AZ (40 mg/kg), MS-275 (20 mg/kg) and AZ + MS-275 (40 + $20 \mathrm{mg} / \mathrm{kg})$ treatments (14D) 
a

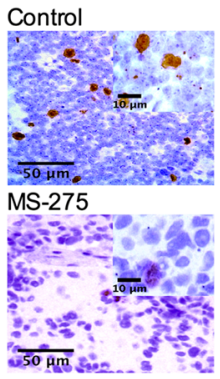

c
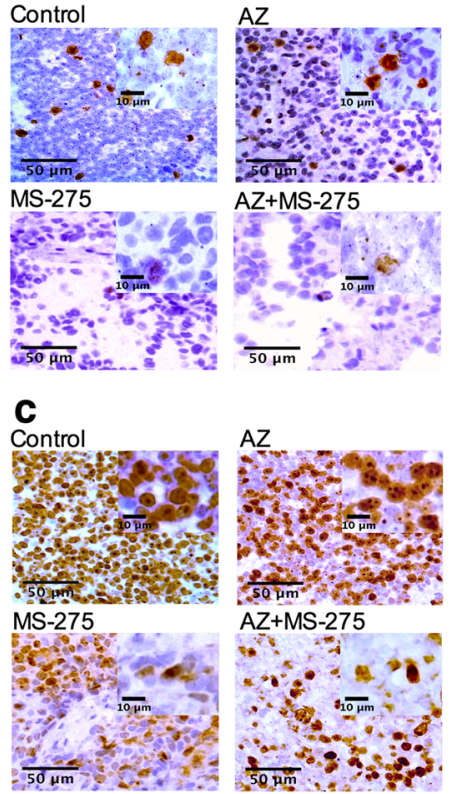

b

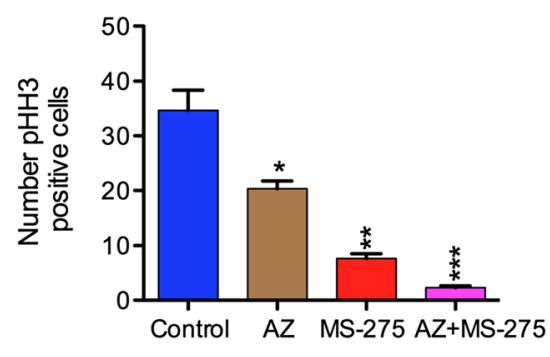

d

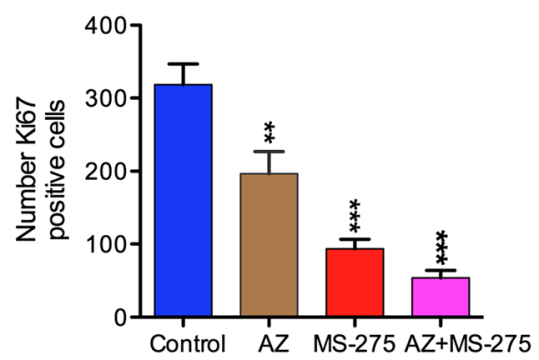

Fig. $7 \mathrm{AZ}$ and/or MS-275 treatments affected the mitosis and proliferation of NB xenografts. $\mathbf{a}$ - $\mathbf{b}$ present the IHC study ( $x 20$ and $\times 40)$ of the mitotic index ( $\mathrm{pHH} 3$, arrow) and the number of $\mathrm{pHH} 3$ positive cells. c-d present the immunodetection and number of Ki67 positive cells (arrow) after 14 days treatment with AZ, MS-275 and AZ + MS-275 compared to untreated group in SH-SY5Y xenografts. Data shows that pHH3 expression was significantly reduced by AZ (42 $\pm 0.43 \% ; p=0.02)$, MS-275 (78 $\pm 0.16 \% ; p=0.002)$ and further by AZ + MS-275 (94 $\pm 0.05 \% ; p=0.001)$. Ki67 expression was moderately reduced by AZ (38 $\pm 0.70 \%$; $(p=0.007)$, strongly reduced by MS-275 $(70 \pm 0.25 \% ; p=0.0002)$ and further reduced by AZ + MS- 275 $(84 \pm 0.73 \% ; p=0.0001)$

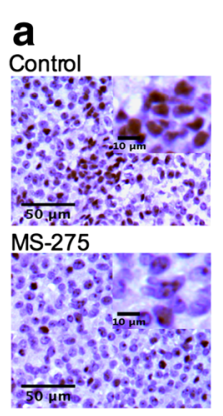

C

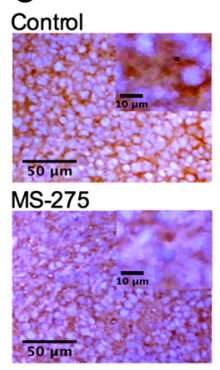

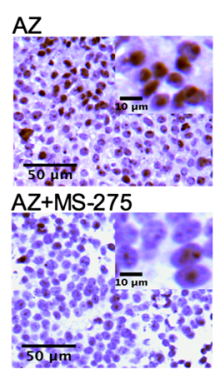

b

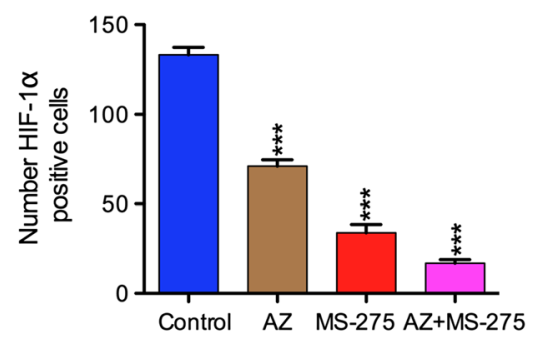

d

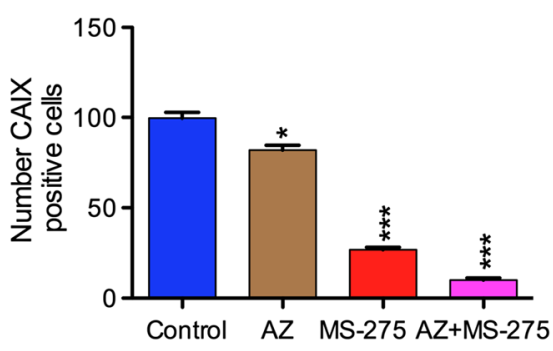

Fig. $8 \mathrm{AZ}$ and/or MS-275 treatments affected hypoxia response and CAIX in NB xenograft cells. a-b present the IHC study ( $x 20$ and $x 40$ ) on HIF1-a expression, (arrow) and the number of HIF-1a positive cells. c-d present CAIX expression (arrow) and the number of CAIX positive cells after 14 days treatment with AZ and/or MS-275 compared to untreated group in SH-SY5Y xenografts. HIF-1a expression was significantly reduced by AZ (29 $\pm 0.7 \% ; p<0.001)$, MS-275 (66 $\pm 0.23 \% ; p<0.001)$ and further enhanced in AZ + MS-275 (83 $\pm 0.67 \% ; p<0.001)$. CAIX expression was significantly reduced by AZ (18 $\pm 0.11 \% ; p=0.0138)$, MS-275 (73 $\pm 0.33 \% ; p<0.001)$ and markedly by AZ + MS275 (90 $\pm 0.16 \% ; p<0.001)$ 
Table 8 Percentage of HIF-1a and CAIX positive cells values of SH-SY5Y tumors

\begin{tabular}{lll}
\hline Treatment modality & $\begin{array}{l}\text { \% Expression of HIF-1a positive cells } \\
(p \text { value })\end{array}$ & $\begin{array}{l}\text { \% Expression of CAIX positive cells } \\
(p \text { value })\end{array}$ \\
\hline AZ & $71 \pm 0.70(p<0.001)$ & $82 \pm 0.11(p=0.0138)$ \\
MS-275 & $34 \pm 0.23(p<0.001)$ & $27 \pm 0.33(p<0.001)$ \\
AZ + MS-275 & $17 \pm 0.73(p<0.001)$ & $10 \pm 0.16(p<0.001)$ \\
\hline
\end{tabular}

Table 8 shows the percentage of SH-SY5Y tumors by AZ (40 mg/kg), MS-275 $(20 \mathrm{mg} / \mathrm{kg})$ and AZ + MS-275 $(40+20 \mathrm{mg} / \mathrm{kg})$ treatments (14D)

SK-N-BE(2), and in comparison to the teratocarcinoma cell line, NT2 with a prevalent stem cell phenotype. MS275 significantly inhibited clonogenic potential of $\mathrm{SH}-$ SY5Y and SK-N-BE(2) cells (Fig. 10a-c). Here we first established an effective concentration range for abrogating clonogenicity in methycellulose, the reduction in the presumptive tumor initiating SP cell fraction (Fig. 11a-b), compared MS-275 with TSA and found MS-275 to be more potent (Fig. 11c-d) while cisplatin (CDDP) was ineffective and reduction in expression of stem cell markers OCT4 and SOX2 by FACs and western blot analysis (Fig. 12a-h). These studies established the ability of MS275 to reduce the tumor initiating potential of NB MYCN NB amplified cell lines. However, to expand upon these studies using immunophenotyping to determine the role of specific stemness markers (OCT4, SOX2, Nanog), we applied IHC to our SH-SY5Y xenografts after AZ, MS-275 and $\mathrm{AZ}+\mathrm{MS}-275$ treatments. We found that the $\mathrm{AZ}+$ MS-275 treatment produced the highest reduction in OCT4 expression, number of SOX2 positive cells, and Nanog immunopositive cells (Table 9; Fig. 13a-f). It is interesting to note that OCT4 and SOX2 expressions were most affected by AZ treatment, and relative to Nanog, proportionally greatest after $\mathrm{AZ}+\mathrm{MS}-275$ treatment, again supporting the idea of AZ potentiation of MS-275.

\section{Discussion}

HDACis are currently being evaluated in cancer clinical trials including NB with still promising results [32]. Whether these like SAHA and MS-275 could become routinely a

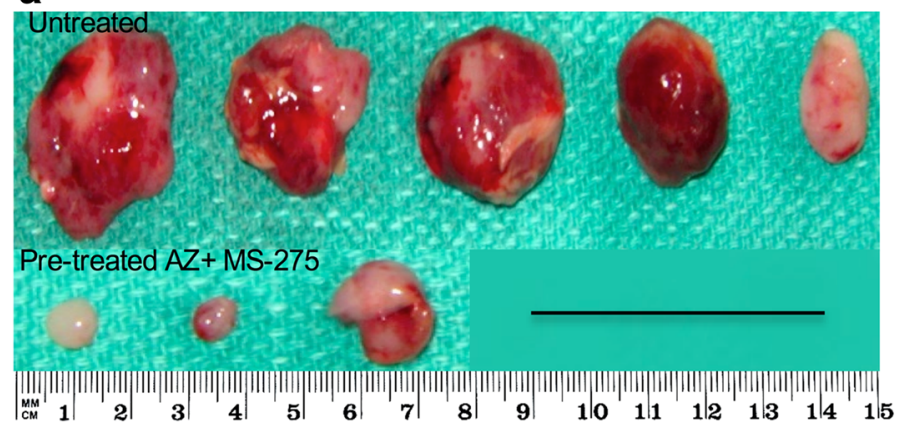

C

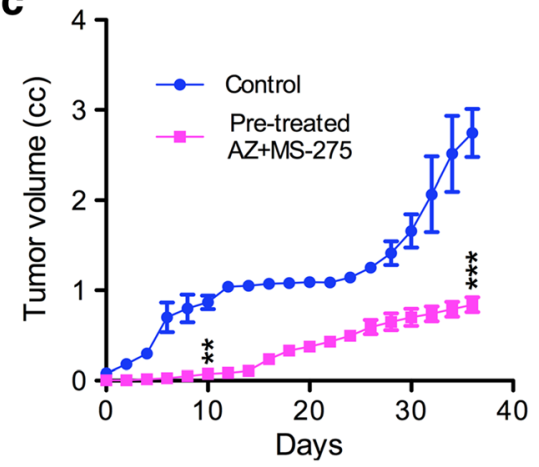

d

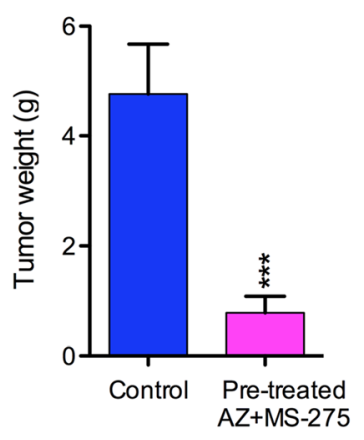

b

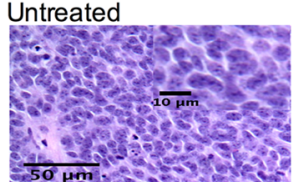

Pre-treated AZ+ MS-275

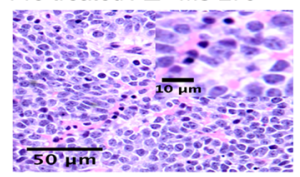

Fig. 9 AZ + MS-275 decreased the in vivo tumorigenic potential of pretreated NB SH-SY5Y cells. a presents the in vivo serial heterotransplantation study ( $\times 20$ and $\times 40$ ) with pretreated NB xenograft cells showing the morphology, $\mathbf{b}$ H\&E histology, $\mathbf{c}$ volume and $\mathbf{d}$ weight after 37 days treatment with AZ + MS-275 compared to untreated group in SH-SY5Y xenografts. Notably, AZ + MS-275 caused a significant reduction in tumor volumes (69 $\pm 0.84 \%$; $p=0.0002)$ and weights $(81 \pm 0.78 \% ; p=0.0001)$ after 37 days compared to xenografts generated from untreated cells 

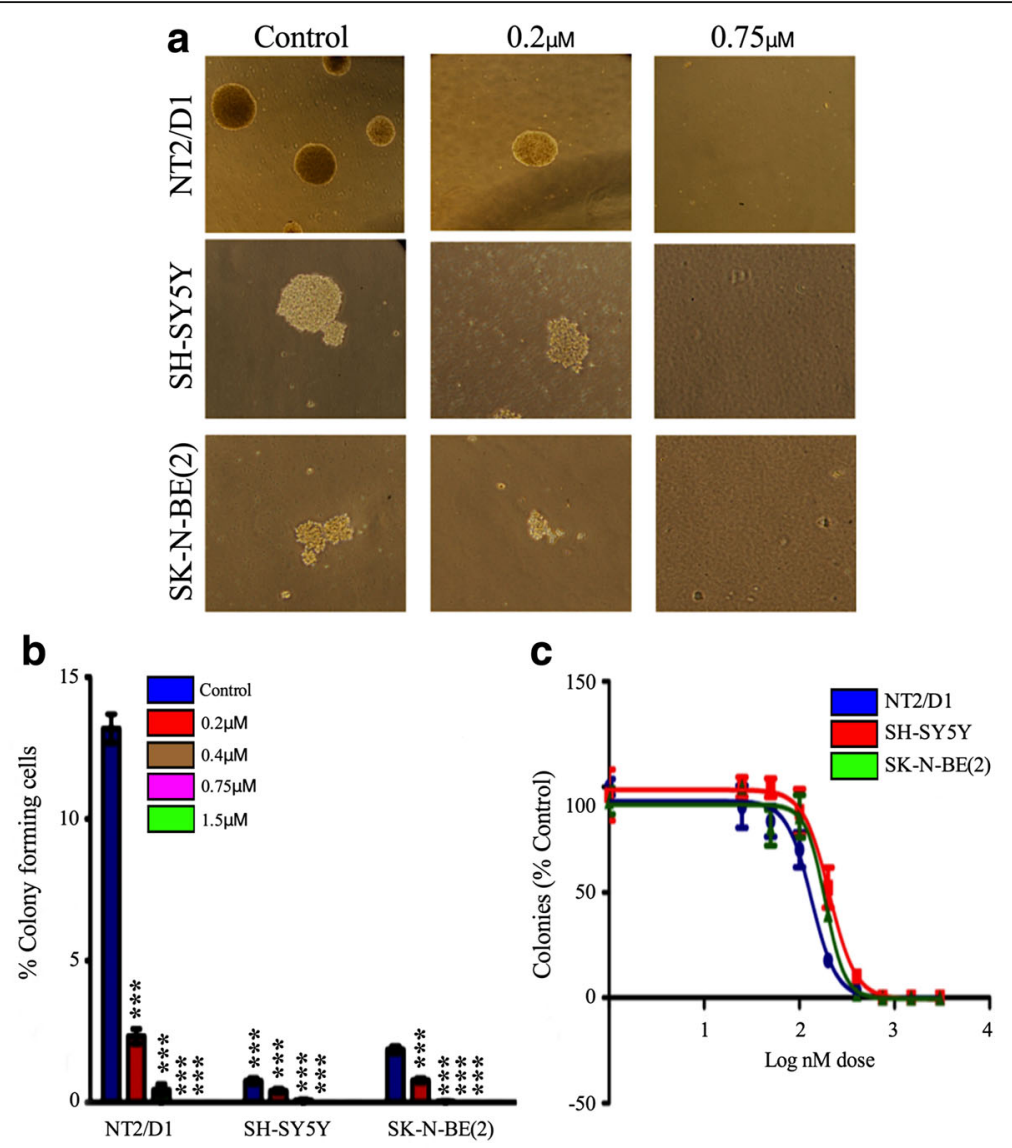

Fig. 10 MS-275 treatment reduced clonogenic potential of NB and teratocarcinoma cells. a clonogenic potential was negatively affected with increasing doses of MS-275. $\mathbf{b}$ dose response curves of MS-275 treatment of NT2/D1, SH-SY5Y and SK-N-BE(2) over a 2 week growth period in methycellulose compared to control. Similarly, clonogenic capacity was negatively affected in all three cell lines despite different initial clonogenic efficiencies. IC50 values were calculated to be $0.13 \mu \mathrm{M}, 0.20 \mu \mathrm{M}$ and $0.18 \mu \mathrm{M}$ for NT2/D1, SH-SY5Y and SK-N-BE(2), respectively. c representative images for control, $0.2 \mu \mathrm{M}$ and $0.75 \mu \mathrm{M}$ MS-275 treatments in methycellulose clonogenic assay run on NT2/D1 and SK-N-BE(2)

administered is currently undecided. However, little has been done to determine if these could be potentiated with other approved drugs and in particular drugs like AZ which can be repurposed based on sound reasoning given knowledge about $\mathrm{pH}$ regulation in tumor cells. We took this latter approach and now report that AZ, MS-275 and especially the AZ + MS-275 combination inhibited migration, in vitro growth, induced cell cycle arrest and apoptosis of NB SH-SY5Y. In addition, the combination markedly inhibited tumor growth in vivo, reduced tumorigenicity and expression of mitosis, proliferative, HIF1- $\alpha$ and CAIX markers in NB SH-SY5Y xenografts. Importantly, we provide additional evidence that MS-275, at nanomolar concentrations, significantly reduced the tumor initiating cell fraction in NB SH-SY5Y and SK-N-BE. The significant reduction in initial tumorigenicity and subsequent serial heterotransplantation suggests either potential elimination or reprogramming of $\mathrm{NB}$ tumor initiating cells. Moreover, stemness genes (OCT4,
SOX2 and Nanog) were found to be significantly down-regulated after MS-275 and the effect was enhanced by AZ + MS-275 treatment.

MS-275 has been previously shown to induce a potent G1 cell cycle arrest in NB studies [33, 34]. We confirmed this key G1 cell cycle arrest and provided evidence that dysregulation of the G1 entry checkpoint in NB is likely due to Cyclin D1 overexpression [34]. Cell cycle inhibitors that modulate cyclinD/CDK4 complex are important in G1 cell cycle arrest [8, 34]. Cyclin D1 and CDK4 knockdown results in proliferation inhibition, G1 cell cycle arrest and neuronal differentiation [35]. In this study we show that MS-275 treatment significantly reduced the expression of cyclin D1 and CDK4 relative to controls. It is not clear whether this reduction results from a direct effect of MS-275 or involves a more downstream mechanism. It has been shown that HDACi can induce the p21 cell cycle inhibitor [36]. Similarly, we found that p21 and p27 were upregulated 


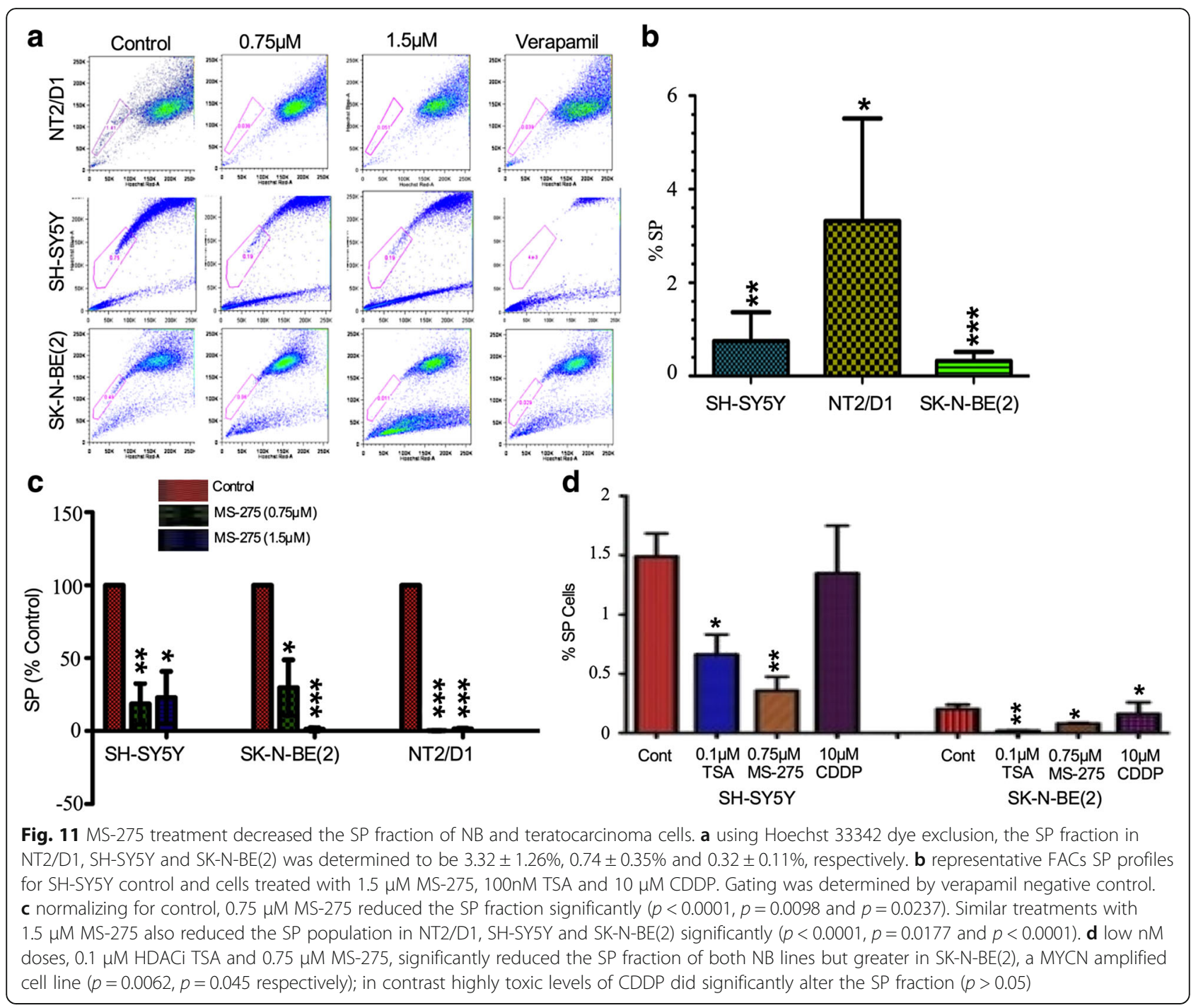

with MS-275 treatment. Interestingly, we observed a dramatic increase in the expression of p16 CDKi. Deregulation of p16 is a common finding in a variety of neoplasms [37], and HDACi have been found to induce p16 in certain types of cancer such as colon carcinoma [38]. Induction of multiple cell cycle inhibitors would be predicted to strongly block cell cycle progression.

MS-275 induces apoptosis through different mechanisms including induction of oxidative stress, the intrinsic and extrinsic pathways of apoptosis [39]. It has been shown by Muhlethaler-Mottet [37] that inducing the intrinsic pathway of apoptosis is the most common mechanism by which HDACi such as TSA, SAHA and $\mathrm{NaB}$ induce apoptosis [40]. Helminthosporium carbonum (HC)-toxin (a natural HDACi) has been shown to decrease the expression of anti-apoptotic BCL2 in NB [41]. We found that the BCL-2/BAX ratio was significantly decreased by MS-275 treatment, indicating induction of the intrinsic pathway of apoptosis. BCL-2/BAX ratio also serves as a predictor of drug efficacy and cancer invasiveness [42].

We surmised that targeted inhibition of CAs by $\mathrm{AZ}$ could interfere with the hypoxia induced HIF1- $\alpha$ mediated regulation of tumor cell $\mathrm{pH}$ homeostasis with likely consequences to other HIF1- $\alpha$ regulated processes required for tumor cell growth, progression, and survival [43]. Since HDACi, such as MS-275 and SAHA, also target HIF1- $\alpha$ activity (e.g. translation [42]) the combination might produce a synergistic effect by blocking the ability of tumor cells to overcome hypoxic stress induced apoptosis $[8,44,45]$. Since the hypoxic niche favors localization of CSCs and their growth and survival [21], our results suggest that CSCs are targeted by the AZ + HDACi combination.

Previous studies have shown that HDAC inhibitors affect migration capacity of tumor cells [46]. The 


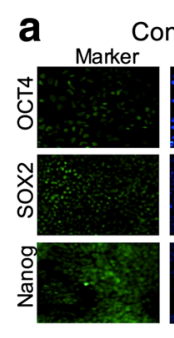

C
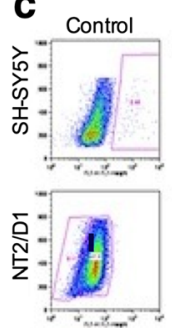

e

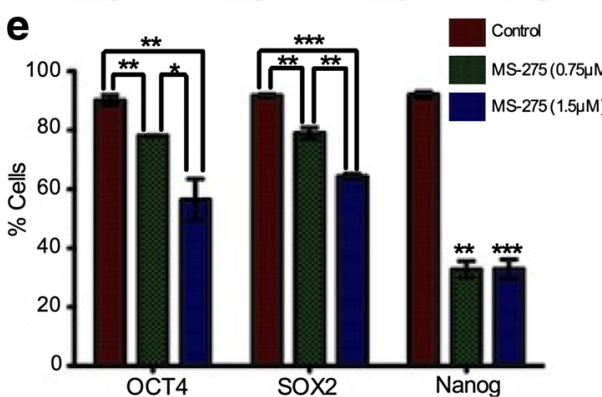

g
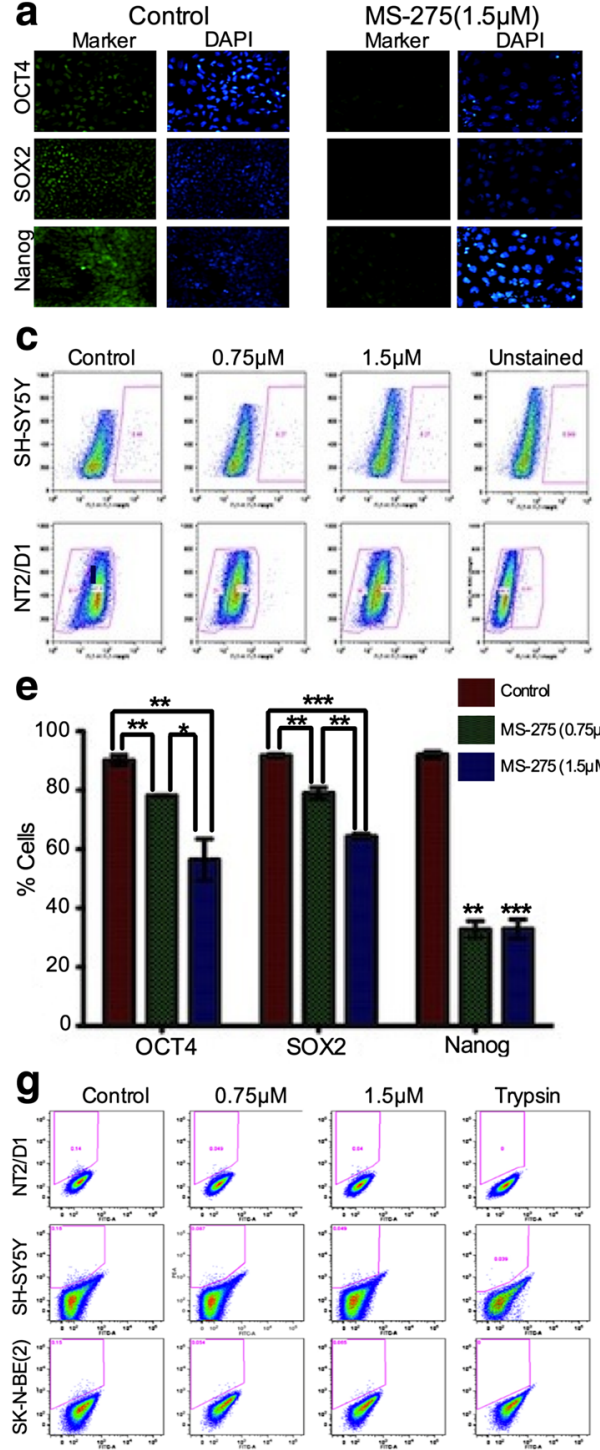

(1)

d
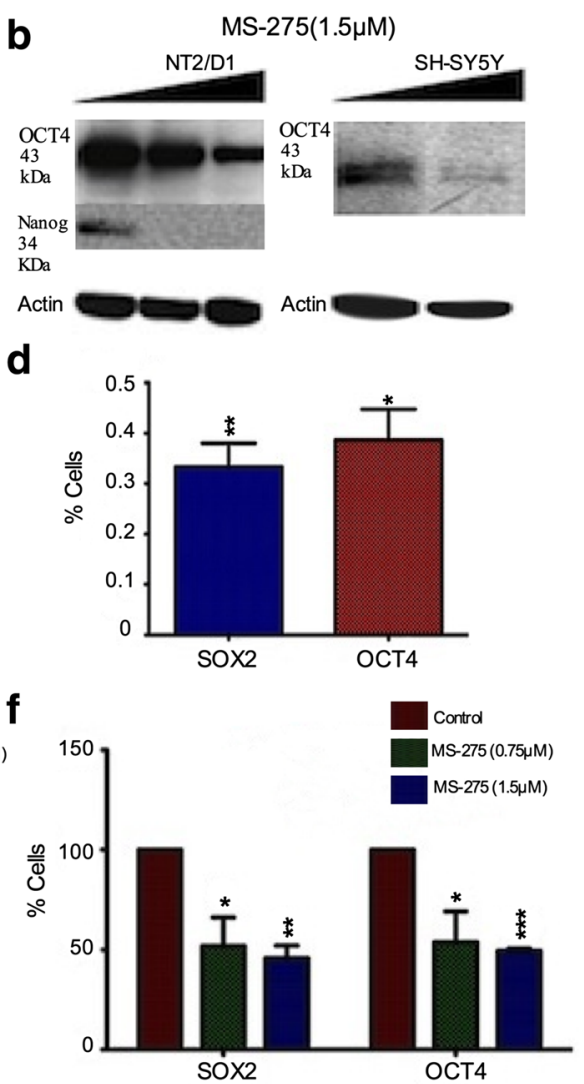

h

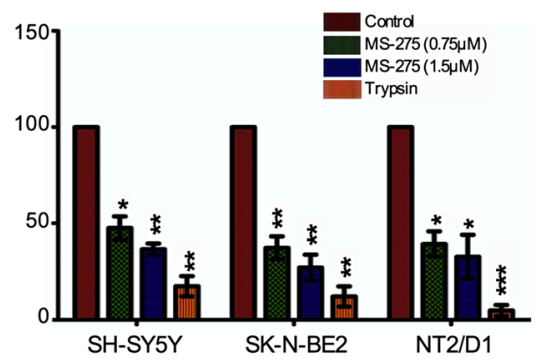

Fig. 12 MS-275 treatment decreased expression of stem cell markers in NB and teratocarcinoma cells. a in the high OCT4, SOX2 and Nanog expressing NT2/D1 teratocarcinoma cell line, MS-275 was able to reduce nuclear expression of these stem cell markers as shown by immunofluorescence labeling. b Western blot analysis demonstrated a MS-275 reduction in expression of OCT4 and Nanog in NT2/D1, and OCT4 in SY5Y. c representative FACs profiles for OCT4 in SH-SY5Y and NT2/D1 cells. $\mathbf{d}$ calculated from FACs data in c. SH-SY5Y contains $0.38 \pm 0.06 \%$ OCT4 positive and $0.33 \pm 0.04 \%$ SOX2 positive cells. e MS-275 treatment significantly reduced expression of OCT4, SOX2 and Nanog in NT2/D1 at 0.75 $\mu M$ $(p=0.0024, p<0.0001$ and $p=0.0031$, respectively) and at $1.5 \mu \mathrm{M}(p=0.0096, p<0.0001$ and $p=0.0023$, respectively). $\mathbf{f}$ when normalized to percentage of control, MS-275 treatment significantly reduced expression of OCT4 and SOX2 in SH-SY5Y at $0.75 \mu \mathrm{M}(p=0.0480$ and $p=0.0391$, respectively) and $1.5 \mu \mathrm{M}(p=0.0003$ and $p=0.0066$, respectively). $\mathbf{g}$ representative FACS profile for ABCG2 staining in SH-SY5Y and SK-N-BE(2) NB cell lines. $\mathbf{h}$ ABCG2 expression significantly decreases following MS-275 treatment in SH-SY5Y, SK-N-BE(2) and NT2/D1 cells at $0.75 \mu M(p=0.0111, p=0.0131$ and $p=0.0086$, respectively) and at $1.5 \mu \mathrm{M}(p=0.027, p=0.0022$ and $p=0.0084$, respectively). Trypsin cleavage of cell surface ABCG2 was used as a negative control

combination of trichostatin A (HDACi) and decitabine effectively decreased migration capacity of ovarian cancer cell line SKOV3 [47]. MS-275 treatment reduced migration capacity of leukemia cells [48]. Epigenetic modifications by HDACi play a key role in regulating the expression of proteins that promote or suppress tumor cell migration [49]. Tumor cell migration capacity is also enhanced by activation of the HIF1- $\alpha$ pathway [50], which in turn regulates CA activity. Therefore, CA inhibitors could decrease migration capacity of tumor cells. Invasion and migration are key components of the metastatic process. Here we show that the AZ + MS-275 
Table 9 Percentage of OCT4, SOX2 and Nanog positive cells values of SH-SY5Y tumors

\begin{tabular}{lll}
\hline Stem cell marker & Treatment modality & $\begin{array}{l}\text { \% Expression of positive } \\
\text { cells }(p \text { value })\end{array}$ \\
\hline OCT4 & AZ & $63 \pm 0.35(p<0.05)$ \\
& MS-275 & $37 \pm 0.85(p<0.001)$ \\
SOX2 & AZ + MS-275 & $18 \pm 0.45(p<0.05)$ \\
& AZ & $68 \pm 0.60(p<0.01)$ \\
& MS-275 & $39 \pm 0.50(p<0.009)$ \\
Nanog & AZ + MS-275 & $18 \pm 0.46(p<0.002)$ \\
& AZ & $89 \pm 0.60(p<0.01)$ \\
& MS-275 & $46 \pm 0.45(p<0.01)$ \\
& AZ + MS-275 & $30 \pm 0.76(p<0.01)$
\end{tabular}

Table 9 shows the percentage of SH-SY5Y tumors by AZ (40 mg/kg), MS-275 $(20 \mathrm{mg} / \mathrm{kg})$ and $\mathrm{AZ}+\mathrm{MS}-275(40+20 \mathrm{mg} / \mathrm{kg})$ treatments (14D)

combination significantly affected tumor cell migration using a wound healing assay concomitant with effects on growth and tumor cell survival. Thus the wound healing assay has limitations but effects on confluent cultures may predict subsequent in vivo results.

Our observations of a potentiated anti-tumor effect by $\mathrm{AZ}+\mathrm{MS}-275$ using the different assays questioned whether the effects were synergistic. In fact simple interpretations of the data might deduce synergism with certain parameters and additively with others. We therefore undertook to analyze the effects by CDI analysis and found that in monolayer cultures the combination was antagonistic at all concentrations on NSC6539 cells and additive on NSC6562 cells at concentrations above $20 \mu \mathrm{M}$ AZ. On NB tumor cell line SH-SY5Y the combination was additive at $40 \mu \mathrm{M}$ and $80 \mu \mathrm{M}$ of $\mathrm{AZ}$ and synergistic at $160 \mu \mathrm{M}$ of AZ. Since the combination was additive or antagonistic at all concentrations on neural stem cells, while additive or synergistic above IC50 on SH-SY5Y cells, CDI values indicate that the combination of acetazolamide and MS-275 was specifically cytotoxic on tumor cells. In fact, further in vivo results support the notion that the AZ + MS-275 combination was indeed potently cytotoxic for NB tumor cells.

Metastasis is a major problem in advanced stage NB. As indicated we found that the AZ + MS-275 combination significantly decreased migration of the SH-SY5Y tumor cells. We asked whether a key molecular contributor to the metastatic phenotype, CAIX, which has been well documented to play a role in tumor development and metastasis, was affected [51]. CAIX expression was found to be dramatically decreased by $\mathrm{AZ}+$ MS-275, suggesting that this combination treatment might indeed block metastatic behavior. CAIX is induced by HIF1- $\alpha$, and HIF1- $\alpha$ knockdown significantly decreased proliferation, migration and invasiveness of NB cell lines [50, 52]. HIF1- $\alpha$ expression is regulated by $\mathrm{PI} 3 \mathrm{~K} / \mathrm{AKT}$ signaling, which is blocked by HDAC inhibition [53-55]. Similar inhibitory effect on the expression of the hypoxia mediated axis in breast cancer cells has been reported for MS-275 [56]. Here, we showed that the AZ + MS-275 combination was most effective in coordinately reducing the number of HIF1- $\alpha$ and CAIX positive cells, correlating with a significant reduction in tumorigenic and likely metastatic potential. Taken together our findings indicate the AZ + MS-275 treatment regimen could interfere with $\mathrm{NB}$ metastasis at multiple levels.

MS-275 has recently been determined to be an inhibitor of the mTOR pathway by upstream modulation of AKT [55]. The mTOR pathway has also been associated with the regulation and modulation of HIF1- $\alpha$, which can modulate and regulate CSCs and the stem cell phenotype [57]. Indeed, we previously showed that hypoxia induced HIF1- $\alpha$ signaling enhances the CSC phenotype in NB side populations (SP) [58]. CSCs are enriched in the SP fraction, a subpopulation defined by the ability to exclude the DNA-binding Hoechst 33342 dye $[59,60]$. These SP cells in NB express high levels of stem cell markers, show increased tumorigenicity, and expand under hypoxia [56]. HDACi have been shown to modulate the HIF1- $\alpha$ mediated pathway by targeting HIF1- $\alpha$ towards proteosomal degradation and by repressing transactivation $[61,62]$. While the modulation of AKT, mTOR and the HIF mediated pathways by HDACi is not yet fully characterized, it offers mechanistic insight showing the multiple targets for how MS275 could be targeting CSCs (schematically shown in Fig. 14). Commonalities in signaling and gene expression has been found between normal stem cells and CSC; as such, drugs targeting normal stem cells should be investigated for their potential ability to deplete the CSC compartment.

Cancers with high percentages of cells expressing the stemness markers, OCT4 and Nanog, have been associated with prognostically poor phenotypes [63]. In this study, we showed that the combination of AZ + MS-275 significantly decreased the number of OCT4, Nanog and SOX2 positive cells in NB xenografts. In addition, we found that treatment with MS-275 significantly reduced the percentage of cells expressing OCT4, SOX2 and Nanog in NB and in a high stemness phenotype teratocarcinoma cell line. Decrease in expression of these stem cell markers in teratocarcinoma is associated with differentiation and loss of the stem cell phenotype. We also found MS-275 treatment reduced the expression of these stemness related genes in the SP fraction, taken as another means of identifying a fraction containing CSCs. NB SP cells expel Hoechst 

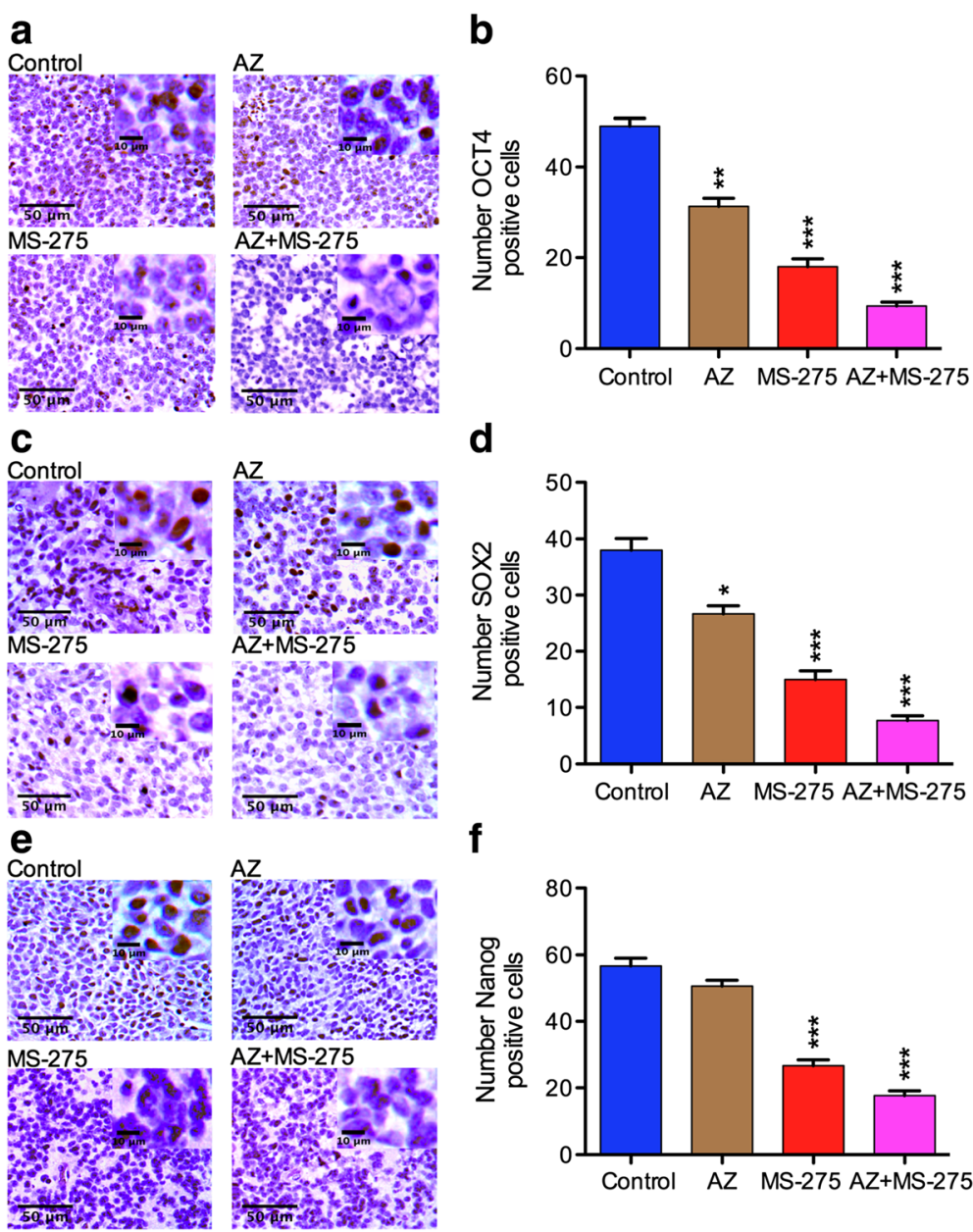

d

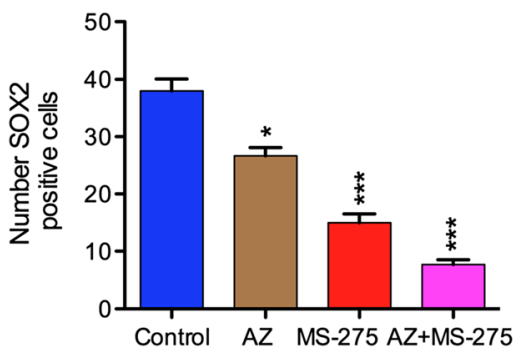

f

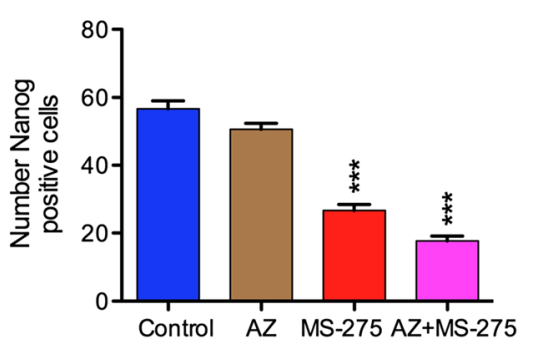

Fig. $13 \mathrm{AZ}$ and/or MS-275 treatments reduced the expression of stem cell markers in NB xenografts. a-b present IHC staining (x20 and x40) for OCT4 cell localization and number of OCT4 positive cells, c-d SOX2 cell localization and number of SOX2 positive cells, and e-f Nanog cell localization and number of Nanog positive cells after 14 days treatment with AZ, MS-275 and AZ + MS-275 compared to untreated group in SH-SY5Y xenografts. The number of OCT4 positive cells was reduced after treatment with AZ by $37 \pm 0.35 \%(p<0.05)$, MS-275 by $63 \pm 0.85 \%(p<0.001)$ and AZ + MS- 275 by $82 \pm 0.45 \%(p<0.001)$. The number of SOX2 positive cells was reduced in AZ by $32 \pm 0.60 \%(p=0.01)$, MS- 275 by $61 \pm 0.5 \%(p=0.0009)$ and AZ + MS- 275 by $82 \pm 0.46 \%(p=0.0002)$. The number of Nanog positive cells was reduced in AZ by $11 \pm 0.60 \%(p>0.05), M S-275$ by $54 \pm 0.45 \%$ $(p=0.0005)$ and $A Z+M S-275$ by $70 \pm 0.76 \%(p=0.0002)$

33342 primarily by means of the ATP-dependent drug pump ABCG2 [58-60]. ABCG2 expression is regulated by $\mathrm{AKT} / \mathrm{PI} 3 \mathrm{~K}$ signaling pathway, which $\mathrm{HDACi}$ is known to inhibit [64].

Finally, it is significant that MYCN non-amplified SH-SY5Y and MYCN amplified SK-N-BE(2) cell line SP fractions were equally targeted by MS-275 treatment. This critical result indicated that MS-275 could target MYCN amplified NB tumors, a group associated with the most aggressive NB phenotype and poor prognosis [1]. Cortes et al. has recently shown that actinomycin D (a member of the actinomycine family) could synergistically potentiate the efficacy of the histone deacetylase inhibitor, SAHA in NB clinical trials. In addition, the combination of actinomycin D with SAHA could inhibit tumor growth in SK-N-JD NB-xenografts [65]. While MS275 or other HDACi such as SAHA are currently in clinical trials as promising anticancer therapeutics, however they still have limitations as single agents [66]. Therefore, a combination of a HDACi with a CA inhibitor affecting $\mathrm{pH}$ homeostasis, may constitute a more effective alternative therapeutic option, as we have reported in other types of cancer $[17,20]$ and as shown here for NB. We surmise that concomitant compromise of $\mathrm{pH}$ homeostasis drives tumor cells into a homeostatic crisis difficult to surmount. Since AZ has been in clinical use over a long period and the pharmacokinetics and side effects are well known and managed [67], it could be readily combined with HDACi already being evaluated in clinical trials for NB. 


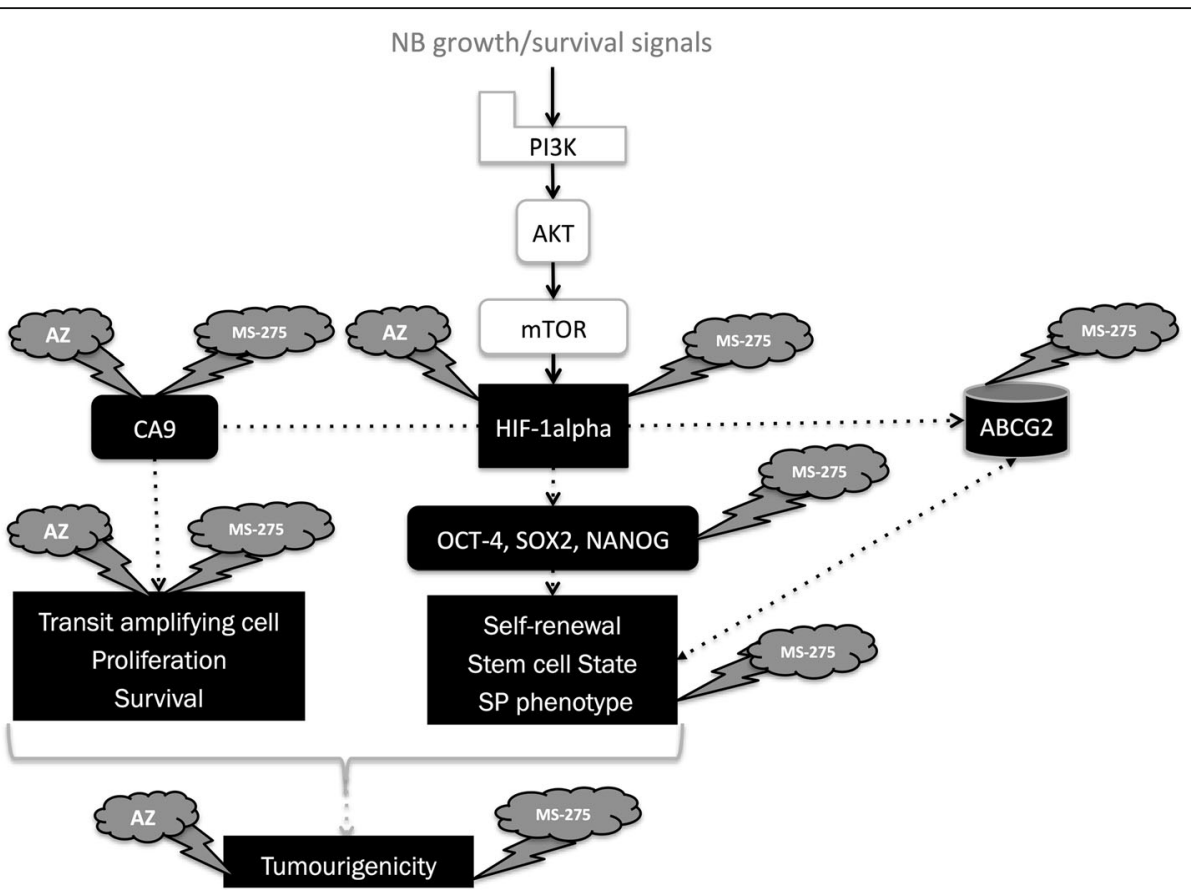

Fig. 14 Schema depicting a potential mechanism of AZ and/or MS-275 treatments in NB cells. As illustrated, AZ, MS-275 and AZ + MS-275 treatments target survival pathways in NB cells. Alterations in cell cycle, and the HIF1-a/CAIX axis by AZ, MS-275 and AZ + MS-275 could affect the NB cell transit amplifying cell population, and its proliferation and survival. Importantly, these treatments could additionally target the CSC in NB by perturbation of self-renewal potential, stem cell state and the SP phenotype. The pan-inhibition of these pathways and critical components would ultimately decrease the tumorigenic potential of NB cells and lead to elimination of the tumor cells

\section{Conclusions}

We present convincing evidence suggesting that the $\mathrm{AZ}+\mathrm{MS}-275$ combination is likely targeting a substantial portion of NB tumor cells in vivo and in particular the CSC population in NB. This finding increases its value in terms of possible management of $\mathrm{NB}$ tumor progression and metastasis using two drugs with known parameters. Since CAIX expression was markedly reduced or abrogated, we propose that AZ+MS-275 should be considered for treatment of the most aggressive NB cases and could find utility for other stages and cases where metastatic progression is predictable from molecular genetic and expression analyses.

\section{Abbreviations}

CAs: Carbonic anhydrases; HDAC: Histone deacetylases; HDACi: Histone deacetylases inhibitor; MS-275: Pyridylmethyl-N-\{4-[(2-aminophenyl)carbamoyl]-benzy|\}-carbamate; NB: Neuroblastoma

\section{Acknowledgments}

We thank Dr. Johann Hitzler, M.D. (The Hospital for Sick Children, Toronto) for critical review of the manuscript.

\section{Funding}

This study was partially supported by James Birrell Neuroblastoma Fund, The Hospital for Sick Children, and the Cancer Research Society, Canada, and the Rally Foundation. Funding agencies had no role in the design of the study and collection, analysis, and interpretation of data and in writing the manuscript.
Availability of data and materials

All relevant materials are included in the manuscript.

\section{Authors' contributions}

RBM initiated the study, designed the experimental approach, conducted the experiments, analyzed the data and wrote the original manuscript. NB assisted the experiments, made the statistical analysis and drafted the manuscript. MKHT, SK and TSH participated in the experiments, assisted the statistical analysis, samples collection and drafting the manuscript. KA, BD and SB assisted in design of the study, coordinated and helped to draft and revised the manuscript. HY conceived the study idea, initiated and supervised the study and revised the manuscript. All authors read and approved the final manuscript.

\section{Competing interests}

The authors declare that they have no competing interests.

Consent for publication

Not applicable.

Ethics approval and consent to participate

The animal use protocols were approved by the Animal Care Committee, Sickkids Research Institute. Animals were treated per guidelines of Canadian Council on Animal Care (CCAC).

\section{Author details}

${ }^{1}$ Developmental and Stem Cell Biology, The Hospital for Sick Children, Toronto, ON, Canada. 'Department of Paediatric Laboratory Medicine, The Hospital for Sick Children, Toronto, ON, Canada. ${ }^{3}$ Institute of Medical Science, University of Toronto, Toronto, ON, Canada. ${ }^{4}$ Department of Paediatrics, Division of Hematology/Oncology, The Hospital for Sick Children, Toronto, ON, Canada. ${ }^{5}$ Department of Pathology and Molecular Medicine, Queen's University, Kingston, ON, Canada. ${ }^{6}$ Department of Immunology and Infectious Diseases, The Forsyth Institute, Cambridge, MA, USA. 
Received: 15 October 2016 Accepted: 8 February 2017 Published online: 24 February 2017

\section{References}

1. Irwin MS, Park JR. Neuroblastoma: paradigm for precision medicine. Pediatr Clin North Am. 2015;62(1):225-56.

2. Dungwa JV, Hunt LP, Ramani P. Carbonic anhydrase IX up-regulation is associated with adverse clinicopathologic and biologic factors in neuroblastomas. Hum Pathol. 2012;43(10):1651-60.

3. Bolden JE, Peart MJ, Johnstone RW. Anticancer activities of histone deacetylaseinhibitors. Nat Rev Drug Discov. 2006;5(9):769-84.

4. Ngamphaiboon N, Dy GK, Ma WW, Zhao Y, Reungwetwattana T, DePaolo D, Ding Y, Brady W, Fetterly G, Adjei AA. A phase I study of the histone deacetylase (HDAC) inhibitor entinostat, in combination with sorafenib in patients with advanced solid tumors. Invest New Drugs. 2015;33(1):225-32

5. Gore S: MS-275 and Azacitidine in Treating Patients With Myelodysplastic Syndromes, Chronic Myelomonocytic Leukemia, or Acute Myeloid Leukemia. National Cancer Institute (NCI).2016; NCT00101179.

6. Rettig I, Koeneke E, Trippel F, Mueller WC, Burhenne J, Kopp-Schneider A, Fabian J, Schober A, Fernekorn U, von Deimling A, et al. Selective inhibition of HDAC8 decreases neuroblastoma growth in vitro and in vivo and enhances retinoic acid-mediated differentiation. Cell Death Dis. 2015;6, e1657.

7. Bieliauskas AV, Pflum MK. Isoform-selective histone deacetylase inhibitors. Chem Soc Rev. 2008;37(7):1402-13.

8. Jaboin J, Wild J, Hamidi H, Khanna C, Kim CJ, Robey R, Bates SE, Thiele CJ. MS-27-275, an inhibitor of histone deacetylase, has marked in vitro and in vivo antitumor activity against pediatric solid tumors. Cancer Res. 2002; 62(21):6108-15.

9. Frumm SM, Fan ZP, Ross KN, Duvall JR, Gupta S, VerPlank L, Suh BC, Holson E, Wagner FF, Smith WB, et al. Selective HDAC1/HDAC2 inhibitors induce neuroblastoma differentiation. Chem Biol. 2013;20(5):713-25.

10. Thurn KT, Thomas S, Moore A, Munster PN. Rational therapeutic combinations with histone deacetylase inhibitors for the treatment of cancer. Future Oncol. 2011;7(2):263-83.

11. Groh T, Hrabeta J, Khalil MA, Doktorova H, Eckschlager T, Stiborova M. The synergistic effects of DNA-damaging drugs cisplatin and etoposide with a histone deacetylase inhibitor valproate in high-risk neuroblastoma cells. Int J Oncol. 2015;47(1):343-52.

12. Ilardi G, Zambrano N, Merolla F, Siano M, Varricchio S, Vecchione M, De Rosa G, Mascolo M, Staibano S. Histopathological determinants of tumor resistance. a special look to the immunohistochemical expression of carbonic anhydrase IX in human cancers. Curr Med Chem. 2014;21(14):1569-82.

13. Ameis HM, Drenckhan A, Freytag M, Izbicki JR, Supuran CT, Reinshagen $K$, Holland-Cunz S, Gros SJ. Carbonic anhydrase IX correlates with survival and is a potential therapeutic target for neuroblastoma. J Enzyme Inhib Med Chem. 2016;31(3):404-9.

14. Kaluz S, Kaluzova M, Stanbridge EJ. Proteasomal inhibition attenuates transcriptional activity of hypoxia-inducible factor 1 (HIF-1) via specific effect on the HIF-1alpha C-terminal activation domain. Mol Cell Biol. 2006;26(15): 5895-907.

15. Monti SM, Supuran CT, De Simone G. Anticancer carbonic anhydrase inhibitors: a patent review (2008 - 2013). Expert Opin Ther Pat. 2013;23(6): 737-49.

16. Scozzafava A, Supuran CT. Glaucoma and the applications of carbonic anhydrase inhibitors. Subcell Biochem. 2014;75:349-59.

17. Mokhtari RB, Kumar S, Islam SS, Yazdanpanah M, Adeli K, Cutz E, Yeger H. Combination of carbonic anhydrase inhibitor, acetazolamide, and sulforaphane, reduces the viability and growth of bronchial carcinoid cell lines. BMC Cancer. 2013;13:378.

18. Carlin S, Khan N, Ku T, Longo VA, Larson SM, Smith-Jones PM. Molecular targeting of carbonic anhydrase IX in mice with hypoxic HT29 colorectal tumor xenografts. PLoS One. 2010; 5(5):e10857.

19. Cianchi F, Vinci MC, Supuran CT, Peruzzi B, De Giuli P, Fasolis G, Perigli G, Pastorekova S, Papucci L, Pini A et al. Selective inhibition of carbonic anhydrase IX decreases cell proliferation and induces ceramide-mediated apoptosis in human cancer cells. J Pharmacol Exp Ther. 2010;334(3):710-9.

20. Islam SS, Mokhtari RB, Akbari P, Hatina J, Yeger H, Farhat WA. Simultaneous Targeting of Bladder Tumor Growth, Survival, and Epithelial to-Mesenchymal Transition with a Novel Therapeutic Combination of Acetazolamide (AZ) and Sulforaphane (SFN). Target Oncol. 2016;11(2):209-27.
21. Lock FE, McDonald PC, Lou Y, Serrano I, Chafe SC, Ostlund C, Aparicio S, Winum JY, Supuran CT, Dedhar S. Targeting carbonic anhydrase IX depletes breast cancer stem cells within the hypoxic niche. Oncogene. 2013;32(44):5210-9.

22. Ledaki I, McIntyre A, Wigfield S, Buffa F, McGowan S, Baban D, Li JL, Harris AL. Carbonic anhydrase IX induction defines a heterogeneous cancer cell response to hypoxia and mediates stem cell-like properties and sensitivity to HDAC inhibition. Oncotarget. 2015;6(23):19413-27.

23. Di Bernardo G, Squillaro T, Dell'Aversana C, Miceli M, Cipollaro M, Cascino A, Altucci L, Galderisi U. Histone deacetylase inhibitors promote apoptosis and senescence in human mesenchymal stem cells. Stem Cells Dev. 2009;18(4):573-81.

24. Ramachandran SIJ, Göttgens E, Krieg E, and Hammond E. Epigenetic therapy for solid tumors: highlighting the impact of tumor hypoxia. Genes. 2015;6:935-56.

25. Gallo M, Ho J, Coutinho FJ, Vanner R, Lee L, Head R, Ling EK, Clarke ID, Dirks PB. A tumorigenic MLL-homeobox network in human glioblastoma stem cells. Cancer Res. 2013;73(1):417-27.

26. Xue-Jun Li, YX BM, and Xiao-Qiang Qi. Effects of Acetazolamide Combined with or without $\mathrm{NaHCO}$ on Suppressing Neoplasm Growth, Metastasis and Aquaporin-1(AQP1) Protein Expression. Int J Mol Sci. 2007:8(3):229-40.

27. Wen Hui Lin JLM DJM, Michelle M. Jack, and Robert C. Baxter. Involvment of insulin-like growth factor binding protein-3 in the effects of the histone deacetylase inhibitor MS-275 in hepatoma cells. J Biol Chem. 2011;1-25.

28. Bin K, Shi-Peng Z. Acetazolamide inhibits aquaporin-1 expression and colon cancer xenograft tumor growth. Hepatogastroenterology. 2011;58(110-111): 1502-6.

29. Richalet JP, Rivera M, Bouchet P, Chirinos E, Onnen I, Petitjean O, Bienvenu A, Lasne F, Moutereau S, Leon-Velarde F. Acetazolamide: a treatment for chronic mountain sickness. Am J Respir Crit Care Med. 2005;172(11):1427-33.

30. Juergens RA, Wrangle J, Vendetti FP, Murphy SC, Zhao M, Coleman B, Sebree R, Rodgers K, Hooker CM, Franco N, et al. Combination epigenetic therapy has efficacy in patients with refractory advanced non-small cell lung cancer. Cancer Discov. 2011;1(7):598-607.

31. Henry-Mowatt J, Dive C, Martinou JC, James D. Role of mitochondrial membrane permeabilization in apoptosis and cancer. Oncogene. 2004;23(16):2850-60.

32. Mottamal M, Zheng S, Huang TL, Wang G. Histone deacetylase inhibitors in clinical studies as templates for new anticancer agents. Molecules. 2015; 20(3):3898-941.

33. Magnaghi-Jaulin L, Ait-Si-Ali S, Harel-Bellan A: Histone acetylation and the control of the cell cycle. Prog Cell Cycle Res. 2000;4:41-7.

34. Molenaar JJ, Ebus ME, Koster J, van Sluis P, van Noesel CJ, Versteeg R, Caron $\mathrm{HN}$. Cyclin D1 and CDK4 activity contribute to the undifferentiated phenotype in neuroblastoma. Cancer Res. 2008;68(8):2599-609.

35. Hardwick $L$, Ali FR, Azzarelli R, Philpott A. Cell cycle regulation of proliferation versus differentiation in the central nervous system. Cell Tissue Res. 2015;359(1):187-200.

36. Takai N, Ueda T, Nishida M, Nasu K, Narahara H. Histone deacetylase inhibitors induce growth inhibition, cell cycle arrest and apoptosis in human choriocarcinoma cells. Int J Mol Med. 2008;21(1):109-15.

37. Romagosa C, Simonetti S, Lopez-Vicente L, Mazo A, Lleonart ME, Castellvi J, Ramon y Cajal S. p16(Ink4a) overexpression in cancer: a tumor suppressor gene associated with senescence and high-grade tumors. Oncogene. 2011; 30(18):2087-97.

38. Wang L, Chen $H_{1}$ Yu J, Lin X, Qi J, Cui C, Xie L, Huang S. CPP2-p16MIS treatment-induced colon carcinoma cell death in vitro and prolonged lifespan of tumor-bearing mice. BMC Cancer. 2016;16:571.

39. Gao S, Mobley A, Miller C, Boklan J, Chandra J. Potentiation of reactive oxygen species is a marker for synergistic cytotoxicity of MS-275 and 5azacytidine in leukemic cells. Leuk Res. 2008;32(5):771-80.

40. Muhlethaler-Mottet A, Flahaut M, Bourloud KB, Auderset K, Meier R, Joseph JM, Gross N. Histone deacetylase inhibitors strongly sensitise neuroblastoma cells to TRAIL-induced apoptosis by a caspases-dependent increase of the pro- to antiapoptotic proteins ratio. BMC Cancer. 2006;6:214.

41. Deubzer HE, Ehemann V, Westermann F, Heinrich R, Mechtersheimer G, Kulozik AE, Schwab M, Witt O. Histone deacetylase inhibitor Helminthosporium carbonum(HC)-toxin suppresses the malignant phenotype of neuroblastoma cells. Int J Cancer. 2008;122(8):1891-900.

42. Matsumoto H, Wada T, Fukunaga K, Yoshihiro S, Matsuyama H, Naito K. Bax to $\mathrm{BCl}-2$ ratio and $\mathrm{Ki}-67$ index are useful predictors of neoadjuvant chemoradiation therapy in bladder cancer. Jpn J Clin Oncol. 2004;34(3):124-30. 
43. Parks SK, Chiche J, Pouyssegur J. pH control mechanisms of tumor survival and growth. J Cell Physiol. 2011;226(2):299-308.

44. Deubzer HE, et al. Anti-neuroblastoma activity of Helminthosporium carbonum(HC)-toxin is superior to that of other differentiating compounds in vitro. Cancer Lett. 2008;264(1):21-8.

45. Hutt DM, Roth DM, Vignaud H, Cullin C, Bouchecareilh M. The histone deacetylase inhibitor, Vorinostat, represses hypoxia inducible factor 1 alpha expression through translational inhibition. PLoS One. 2014;9(8):e106224.

46. Dokmanovic M, Clarke C, Marks PA. Histone deacetylase inhibitors: overview and perspectives. Mol Cancer Res. 2007;5(10):981-9.

47. Meng F, Sun G, Zhong M, Yu Y, Brewer MA. Anticancer efficacy of cisplatin and trichostatin A or 5-aza-2'-deoxycytidine on ovarian cancer. Br J Cancer. 2013;108(3):579-86.

48. Vire B, de Walque S, Restouin A, Olive D, Van Lint C, Collette Y. Antileukemia activity of MS-275 histone deacetylase inhibitor implicates 4-1BBL/ 4-1BB immunomodulatory functions. PLoS One. 2009;4(9):e7085.

49. Nagelkerke A, Bussink J, Mujcic H, Wouters BG, Lehmann S, Sweep FC, Span PN. Hypoxia stimulates migration of breast cancer cells via the PERKATF4/ LAMP3-arm of the unfolded protein response. Breast Cancer Res. 2013;15(1):R2.

50. Chen SZM, Xing L, Wang Y, Xiao Y, Wu Y. HIF-1alpha contributes to proliferation and invasiveness of neuroblastoma cells via SHH signaling. PloS One. 2015;10(3):e0121115.

51. Robertson N, Potter C, Harris AL. Role of carbonic anhydrase IX in human tumor cell growth, survival, and invasion. Cancer Res. 2004;64(17):6160-5.

52. KL PG. Hypoxia inducible factor-1alpha as a cancer drug target. Mol Cancer Therapeutics. 2004;3(5):647-54.

53. Jiang BH, Liu LZ. PI3K/PTEN signaling in tumorigenesis and angiogenesis. Biochim Biophys Acta. 2008;1784(1):150-8.

54. Jiang BH, Liu LZ. PI3K/PTEN signaling in angiogenesis and tumorigenesis. Adv Cancer Res. 2009;102:19-65.

55. Zhang P, Guo Z, Wu Y, Hu R, Du J, He X, Jiao X, Zhu X: Histone Deacetylase Inhibitors Inhibit the Proliferation of Gallbladder Carcinoma Cells by Suppressing AKT/mTOR Signaling. PLoS One. 2015;10(8):e0136193.

56. Wilson-Edell KA, Yevtushenko MA, Rothschild DE, Rogers AN, Benz CC. mTORC1/C2 and pan-HDAC inhibitors synergistically impair breast cancer growth by convergent AKT and polysome inhibiting mechanisms. Breast Cancer ResTreat. 2014;144(2):287-98.

57. Marhold M, Tomasich E, El-Gazzar A, Heller G, Spittler A, Horvat R, Krainer M, Horak P. HIF1alpha Regulates mTOR Signaling and Viability of Prostate Cancer Stem Cells. Mol Cancer Res. 2015;13(3):556-64.

58. Das B, Tsuchida R, Malkin D, Koren G, Baruchel S, Yeger H. Hypoxia enhances tumor stemness by increasing the invasive and tumorigenic side population fraction. Stem Cells. 2008;26(7):1818-30.

59. Patrawala LCT, Schneider-Broussard R, Zhou J, Claypool K, Tang DG. Side population is enriched in tumorigenic, stem-like cancer cells, whereas ABCG2+ and ABCG2- cancer cells are similarly tumorigenic. Cancer Res. 2005;65(14):6207-19.

60. Bleau AM, Hambardzumyan D, Ozawa T, Fomchenko El, Huse JT, Brennan CW, Holland EC. PTEN/PI3K/Akt pathway regulates the side population phenotype and ABCG2 activity in glioma tumor stem-like cells. Cell Stem Cell. 2009;4(3):226-35.

61. Masoud GN, Li W. HIF-1alpha pathway: role, regulation and intervention for cancer therapy. Acta Pharm Sin B. 2015;5(5):378-89.

62. Liang D, Kong X, Sang N. Effects of histone deacetylase inhibitors on HIF-1. Cell Cycle. 2006;5(21):2430-5.

63. Chiou SH, Yu CC, Huang CY, Lin SC, Liu CJ, Tsai TH, Chou SH, Chien CS, Ku HH, Lo JF. Positive correlations of Oct-4 and Nanog in oral cancer stem-like cells and high-grade oral squamous cell carcinoma. Clin Cancer Res. 2008;14(13):4085-95.

64. Dragu DL, Necula LG, Bleotu C, Diaconu CC, Chivu-Economescu M. Therapies targeting cancer stem cells. Current trends and future challenges. World J Stem Cells. 2015;7(9):1185-201.

65. Cortes CL, Veiga SR, Almacellas E, Hernandez-Losa J, Ferreres JC, Kozma SC, Ambrosio S, Thomas G, Tauler A: Effect of low doses of actinomycin D on neuroblastoma cell lines. Mol Cancer. 2016;15:1.

66. Pharmaceuticals S. A Phase 2 Multi-Center Study of Entinostat (SNDX-275) in Patients With Relapsed or Refractory Hodgkin's Lymphoma. Beverly Hills: Tower Cancer Research Foundaton; Denver: University of Colorado; Baltimore: Johns Hopkins; Omaha: University of Nebraska Medical Center; Buffalo: Roswell Park Cancer Institute; Houston: MD Anderson Cancer Center; 2016; NCT00866333.

67. Seda G, Tsai S, Lee-Chiong T. Medication effects on sleep and breathing Clin Chest Med. 2014;35(3):557-69.

\section{Submit your next manuscript to BioMed Central and we will help you at every step:}

- We accept pre-submission inquiries

- Our selector tool helps you to find the most relevant journal

- We provide round the clock customer support

- Convenient online submission

- Thorough peer review

- Inclusion in PubMed and all major indexing services

- Maximum visibility for your research

Submit your manuscript at www.biomedcentral.com/submit 